\title{
Manipulation of gas-liquid-liquid systems in continuous flow microreactors for efficient reaction processes
}

\author{
Yanyan Liu ${ }^{1,2,3} \cdot$ Guangwen Chen ${ }^{2} \cdot$ Jun Yue ${ }^{1}$ (i) \\ Received: 7 October 2019 / Accepted: 20 November 2019 / Published online: 7 February 2020 \\ (C) The Author(s) 2020
}

\begin{abstract}
Gas-liquid-liquid flow in microreactors holds great potential towards process intensification of operation in multiphase systems, particularly by a precise control over the three-phase contact patterns and the associated mass transfer enhancement. This work reviews the manipulation of gas-liquid-liquid three-phase flow in microreactors for carrying out efficient reaction processes, including gas-liquid-liquid reactions with catalysts residing in either liquid phase, coupling of a gas-liquid reaction with the liquid-liquid extraction, inert gas assisted liquid-liquid reactions and particle synthesis under three-phase flow. Microreactors are shown to be able to provide well-defined flow patterns and enhanced gas-liquid/liquid-liquid mass transfer rates towards the optimized system performance. The interplay between hydrodynamics and mass transfer, as well as its influence on the overall microreactor system performance is discussed. Meanwhile, future perspectives regarding the scale-up of gas-liquid-liquid microreactors in order to meet the industrial needs and their potential applications especially in biobased chemicals and fuels synthesis are further addressed.
\end{abstract}

Keywords Gas-liquid-liquid · Microreactor $\cdot$ Reaction $\cdot$ Slug flow $\cdot$ Mass transfer $\cdot$ Hydrodynamics

\section{Introduction}

Gas-liquid-liquid systems play an important role in both industries and research frontiers within the scope of chemical conversion. For example, many reactions involving gasliquid-liquid three-phase systems have been processed at the industrial scale, such as triphasic catalysis $[1,2]$ (including

\section{Article Highlights}

- The use of gas-liquid-liquid microreactors for carrying out efficient reaction processes is reviewed.

- Triphasic reactions, reaction-extraction coupling, gas assisted biphasic reactions and particle synthesis are discussed.

- Promising applications are highlighted for biobased chemicals and fuels synthesis.

Jun Yue

yue.jun@rug.nl

1 Department of Chemical Engineering, Engineering and Technology Institute Groningen, University of Groningen, 9747, AG Groningen, The Netherlands

2 Dalian National Laboratory for Clean Energy, Dalian Institute of Chemical Physics, Chinese Academy of Sciences, Dalian 116023, China

3 University of Chinese Academy of Sciences, Beijing 100049, China among others hydrogenation [3, 4], hydroformylation [5, 6] and carbonylation [7]) where gas phase reacts with one liquid phase over the catalyst residing in the other liquid phase. The operation of these reactions in conventional reactors (e.g., bubble column reactors and stirred tank reactors) often suffers from the insufficient mass/heat transfer and a poor control over the contact patterns between reactive phases, leading to typically low reaction conversions and the unsatisfactory system reproducibility as well as an unreliable system performance prediction. In this respect, an advanced reactor technology with fast transfer rates and sufficient phase contacts is preferred towards process optimization.

Microreactors have long been acknowledged as an attractive alternative for process intensification and reaction/ kinetics study [8-10]. This operation platform is composed of small tubes or channels with typical lateral dimensions within ca. $1 \mathrm{~mm}$, but this dimension could be extended reasonably to a few millimeters as long as the benefits due to miniaturization is kept [11]. Fluids delivered into the microreactor are commonly mixed and subsequently dispersed into the reaction microchannel via micromixers (e.g., based on a T- [12-14], Y- [15, 16] or cross-junction [17-19], or flow-focusing geometry $[16,20])$ or membranes $[21,22]$. Due to the laminar flow nature and the dominance of interface 
tension in well-defined microreactor geometries [23], regular multiphase flow patterns (e.g., with the presence of welldefined bubbles or droplets) are easily generated. Along with the reduction of the lateral dimension to typically submillimeter range, substantial mass and heat transfer enhancement is attainable in microreactors. Thus, continuous flow microreactors are expected to improve the reaction conversion especially in multiphase systems, the performance of which tends to be usually confined by either the mass transfer limitation between phases or the poor process control (e.g., in temperature and phase contact pattern). Meanwhile, microreactors allow a fast scale-up by a simple replication of the basic reaction units while maintaining the optimized performance previously achieved in a single microreactor, provided that the fluid distribution and collection are properly addressed [24-26]. This feature shortens the lead time of using microreactor technology for manufacturing a certain product, and especially makes microreactors favorable for the modular and flexible production of value-added and market-oriented products (e.g., pharmaceuticals) the demand of which may vary depending on the seasons and regions etc. [27]. Besides, microreactors are good candidates for reaction and kinetics study [8-10], primarily due to the precise process control and substantial transport intensification therein. In addition, liquid-phase reactions could be confined in separate droplets in microreactors (e.g., if using inert gas bubbles as spacers in between) and thus the corresponding reactive conditions (e.g., catalyst/substrate concentrations and residence times) can be easily altered and tested in a fast fashion [28].

Gas-liquid-liquid operation in microreactors has received increasing research attention over recent years with promising results being obtained in the targeted applications in among others three-phase reactions [11, 29-34], gas-liquid reaction coupled with in-situ extraction [21], inert gas assisted liquidliquid reaction study $[32,35,36]$ and multistep synthesis (e.g., for making nanoparticles) $[19,37,38]$. As previously mentioned, gas-liquid-liquid reaction requires a fine control over the three-phase contact pattern and the associated mass transfer property for obtaining a favorable performance. A switch to continuous flow microreactor operation largely facilitates this, e.g., by creating a uniform bubble and droplet dispersion in another continuous liquid phase and by enhancing mass transfer (e.g., the overall volumetric gas-liquid/liquid-liquid mass transfer rates were reported to be at least 1 or 2 orders of magnitude higher than those in conventional batch and flow reactors, primarily due to the much increased interfacial area therein) $[11,29,30,36,39-42]$. The substantial mass transfer enhancement in gas-liquid-liquid microreactors can lead to higher reaction conversions within a shorter residence time, and probably also a higher selectivity of the target product in case of multiple reactions (e.g., via a fine tuning of the narrowed residence time). Moreover, the coupling between a gas-liquid (catalytic) reaction with an in-situ extraction of the formed target product into the other liquid phase can be performed efficiently under gas-liquid-liquid flow in microreactors which facilitates the creation of a good gasliquid and liquid-liquid contact, thereby improving the efficiency of both the reaction and extraction processes [21]. This coupling has the advantages of improving the target product yield (e.g., due to the equilibrium reaction shift to the product side or the suppression of the product degradation in the reactive liquid phase) or simplifying the process workup (e.g., due to the process integration in one flow). Another promising case is in the inert gas assisted liquid-liquid reaction study in microreactors, where the presence of an inert gas (e.g., as discrete bubbles) into an otherwise liquid-liquid flow in microreactors largely increases the extraction and/or reaction efficiency therein $[36,39,43]$, which can lead to a reduced reaction time or solvent use. The synthesis of nanoparticles can also benefit from three-phase flow processing in microreactors. For instance, when it involves a gas-liquid reaction, an inert carrier fluid flow can be present in microreactors in order to lubricate the droplets where nanoparticles are formed and thus to mitigate the deposition of nanoparticles on the channel wall [44]. When subsequent injections of homogeneous precursors are involved, additional gas bubbles (besides the carrier fluid) can be present in microreactors to enable an accurate mixing of precursors within a single droplet to assure the proper reaction degree [37, 38]. Thus, complex particle synthesis procedures or solid precipitation processes can be well handled using gas-liquidliquid operation in microreactors.

Understanding into transport characteristics within gasliquid-liquid flow in microreactors is of vital importance for the design, operation and optimization of such microreactor systems for their promising applications in the abovementioned fields. Compared with the extensive gas-liquid and liquid-liquid two-phase flow studies in microreactors [23, 45-48], limited research has been paid to the case of gas-liquid-liquid microflow [11, 12, 19, 29]. A considerable fraction of the literature work in the latter case was focused on hydrodynamics therein $[13,14,17,18,49,50]$, and few on the investigation of mass transfer property $[12,14]$ and the preliminary exploration of the potential applications [21, 29, 30, 38]. Fig. 1 shows the representative gas-liquid-liquid flow patterns studied in microreactors so far, including threephase slug flow where gas bubbles and/or liquid droplets are dispersed in the continuous phase (Figs. 1a and b), parallelslug flow where two immiscible liquid phases flow in parallel with gas bubbles residing in either of them (Fig. 1c), churn flow where both bubbles and droplets fail to maintain stable shapes (Fig. 1d), and annular flow where a continuous gas core is surrounded by one continuous liquid phase that contains tiny droplets (Fig. 1e). The parallel-slug flow pattern requires a matching between the flow rates of both liquid phases in order to form a parallel flow configuration and 
Fig. 1 Representative gas-liquidliquid flow patterns in

microreactors, consisting of a and b three-phase slug flow [17, 18]; c parallel-slug flow [17]; $\mathbf{d}$ churn flow and e annular flow [39]. In a, discrete bubbles and droplets are present and their number and sequence in a unit cell designate different sub-regimes (i) to (iii). In b, bubbles and droplets assemble double-emulsion configurations where gas bubbles are encapsulated in liquid droplets (a) Slug flow with discrete bubbles/droplets

(i) alternate bubble-droplet
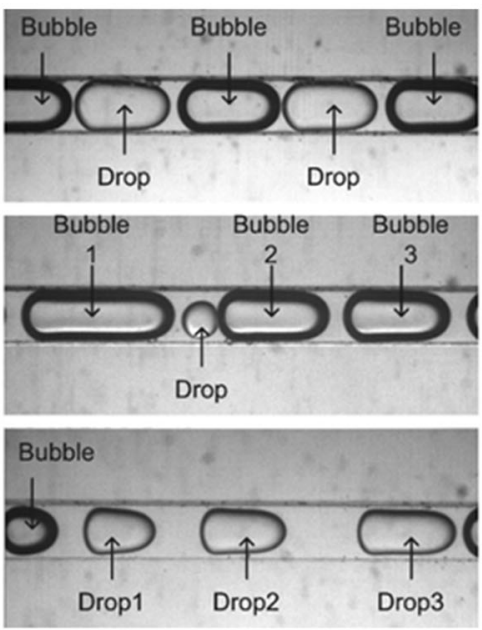

(iii) bubble-multidroplets

(b) Slug flow with double emulsions

Gas-in-oil-in-water

$\mathrm{G} / \mathrm{O} / \mathrm{W}$

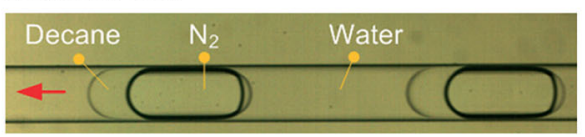

(c) Parallel-slug flow

Gas-in-oil-parallel-with-water (G/O)-W

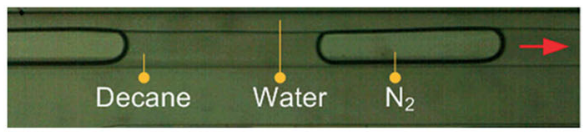

(d) Churn flow

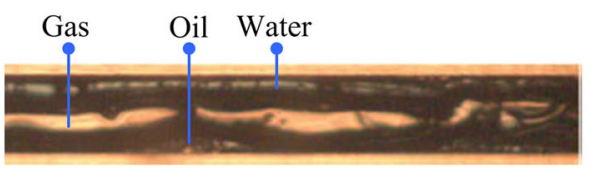

(e) Annular flow

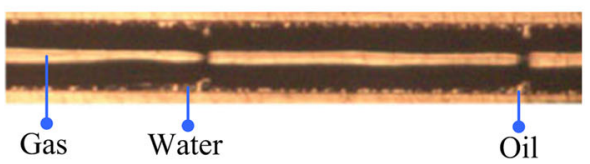

seems to be only reported in the microfluidic chip based on the borosilicate glass [17]. In the churn flow and annular flow, a relatively large gas flow rate is usually needed since the gaseous void fraction is very high [39]. Furthermore, fluctuating interfaces are present and the (gas-liquid and liquid-liquid) interfacial areas between phases are difficult to well determine and control, which makes these flow patterns less ideal to be applied in reaction processes. In contrast, the three-phase slug flow pattern has been commonly utilized for various microreactor applications [21, 29, 30, 36, 38, 51], which could be easily generated under a wide range of operating conditions apart from its well-defined flow giving possibilities for a fine tuning of the transport/reaction property as well as its performance interpretation. Herein, the dispersed phase could be either the discrete bubbles and droplets (e.g., pattern (G-W)/ $\mathrm{O}$ as shown in Fig. 1a; the number of bubbles and droplets in a unit cell can vary depending on the operating conditions, which designates different sub-regimes (i) to (iii)) [13, 14, $18,50,52]$, or double emulsions that consist of bubbles encapsulated in the droplet of one liquid phase (e.g., pattern $\mathrm{G} / \mathrm{O} / \mathrm{W}$ as shown in Fig. 1b) [17]. The structure of such dispersion (i.e., the presence of discrete bubbles/droplets or double emulsions) depends on the balance of the interfacial forces among the involved phases when the viscous forces are negligible [53], as illustrated in Figs. 2a-e. Discrete bubbles/ droplets (Figs. 2b and c) are formed when the interfacial force between the two dispersed phases $\left(\gamma_{t-r}\right)$ is much larger than the other two counterparts (i.e., the interfacial forces between the 

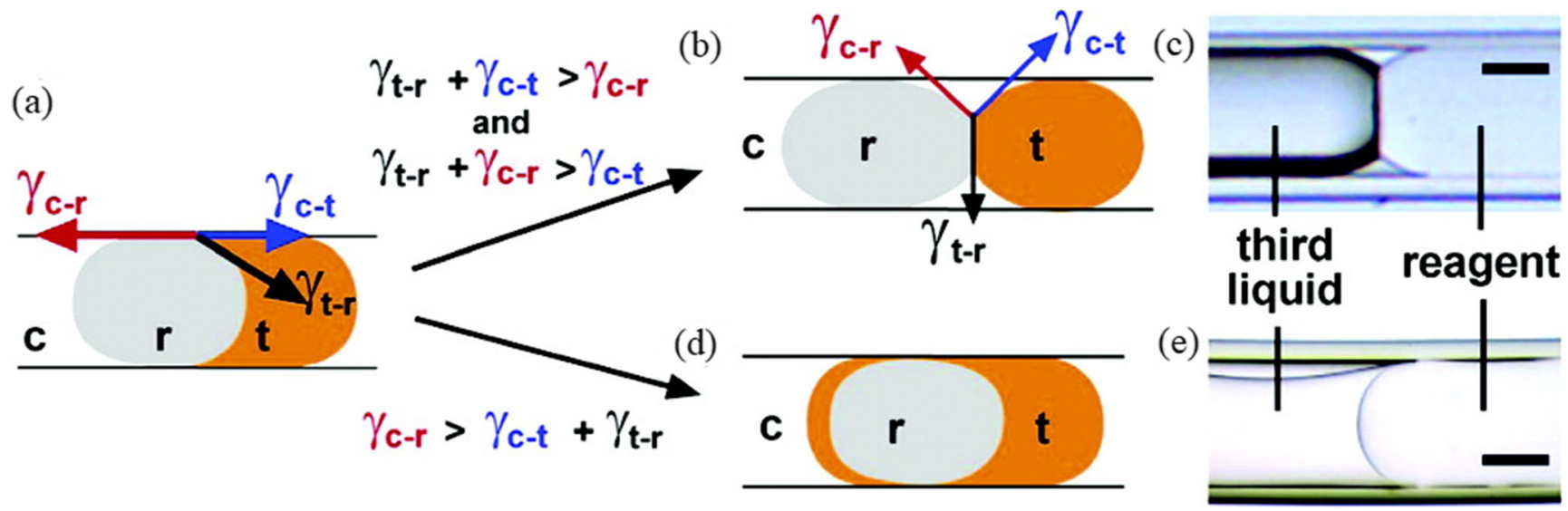

Fig. 2 Interfacial force $(\gamma)$ dominated dispersion structures. a The hypothetical starting point where two dispersed phases (i.e., $r$ and $t$ ) completely contact each other in the carrier fluid (phase c). This status

carrier fluid and either of the dispersed phases, $\gamma_{c-r}$ and $\left.\gamma_{c-t}\right)$. Double emulsions (Figs. 2d-e) are generated when $\gamma_{t-r}$ is relatively small. Herein, one of the dispersed phases having a larger interfacial force with the carrier fluid will be engulfed into the other dispersed phase, implying that for gas-liquidliquid flow bubbles are (often) encapsulated in droplets since it is energetically favorable [54].

Thus, the gas-liquid-liquid slug flow provides more degrees of freedom in its manipulation according to specific reaction needs. In addition, the exact flow patterns including the phase dispersion could be adjusted by changing materials of microreactors or fluids properties [53]. When a gas-liquidliquid reaction process is limited by the mass transfer from the gas to the aqueous phase (e.g., with the aqueous phase containing catalysts or having a low gas solubility), the double-emulsion slug flow pattern with bubbles encapsulated in aqueous droplets might be more preferable than that with discrete bubble-droplet dispersions (Fig. 1a; with the organic phase as the continuous carrier). In the latter case, gas has to be transported to the aqueous phase via the organic phase, thus increasing the mass transfer resistance. However, three-phase slug flow with the presence of discrete bubbles and droplets (Fig. 1a) is expected to be more useful in many applications, since the phasic flow rate can be adjusted to realize various sizes and amounts of bubbles and droplets located in a unit cell in order to obtain a fine control over (gas-liquid and/or liquidliquid) interfacial areas and transfer distances (e.g., by narrowing the film thickness of the continuous phase between bubbles and droplets). When solid particles are involved (e.g., nanoparticle catalysts for use in hydrogenation $[29,30]$ or solid formation during reaction), confining the solid in the dispersed droplets is an effective approach to avoid channel fouling or clogging. When droplets are vulnerable to merge, inert gas bubbles could serve as a spacer to prevent the droplet coalescence in a liquid-liquid reaction. Given all the above merits, one can safely conclude that gas-liquid-liquid slug flow (especially may develop into $\mathbf{b}$ and $\mathbf{c}$ discrete bubbles/droplets or $\mathbf{d}$ and $\mathbf{e}$ double emulsions according to the balance among interfacial forces. The figure is adopted from the work of Chen et al. [53]

with discrete bubbles/droplets) in microreactors holds great potential for gas-liquid-liquid operations.

It is noteworthy that more general aspects on gas-liquidliquid flow in relation to process intensification have been touched very recently in two reviews (e.g., on microfluidics and emulsion preparation [19], and on intensified reactors [55]). However, to the best of our knowledge, there is no comprehensive review so far on summarizing the state of the art in the manipulation of gas-liquid-liquid systems in microreactors for carrying out efficient reaction processes. Therefore, this review is centered around this topic, especially focusing on the related applications (including gas-liquidliquid reaction, reaction-extraction coupling, inert gas assisted liquid-liquid reactions and particle synthesis under threephase flow). The role of transport characteristics (gas-liquidliquid hydrodynamics and mass transfer) therein is further addressed for a better understanding of the system performance. The future perspectives of such gas-liquid-liquid microreactor systems regarding the scale-up to meet the industrial needs and their potential applications particularly in biobased chemicals and fuels synthesis are highlighted.

\section{Applications of gas-liquid-liquid microreactors}

The state of the art of gas-liquid-liquid microreactors is divided based on mainly four different application categories: i) gas-liquid-liquid reactions; ii) reaction-extraction coupling; iii) inert gas assisted liquid-liquid reactions and iv) particle synthesis. For each category, the three-phase hydrodynamics, mass transfer and their interaction with the reaction performance are discussed.

\section{Gas-liquid-liquid reactions}

In gas-liquid-liquid systems with three reactive phases (i.e., triphasic reactions), such as hydrogenation, hydroformylation 
and carbonylation, catalysts usually reside in either of the two liquid phases [11, 30]. Reactions may take place at the liquidliquid interface, gas-liquid interface or within the continuous liquid bulk [2], depending on the solubilities and mass transfer rates of different reactive species in the involved fluids. Despite the fact that these gas-liquid-liquid reactions are of great importance in the field of chemical synthesis, few researches have been done in the past decades. This is because that the reaction performance in conventional reactors is usually subjected to the limited mass transfer rates and the maldistribution of phases, rendering unsatisfactory selectivity and yield [55]. Microreactors, primarily owing to their enhanced mass transfer and uniform three-phase flow patterns, open a new avenue for process intensification and reaction/kinetic studies, especially for fast gas-liquid-liquid reactions such as hydrogenation and hydroformylation. In these triphasic reactions, both homogeneous and heterogeneous catalysts may be involved, and the corresponding operations in gas-liquidliquid microreactors will be elaborated hereafter.

\section{Homogeneous catalysis}

As the first report of gas-liquid-liquid reactions operated in a microreactor, Önal et al. [29] carried out the selective hydrogenation of $\alpha$, $\beta$-unsaturated aldehydes to unsaturated alcohols (which are widely used in pharmaceuticals, fragrance and flavor chemicals [56]). The reaction was catalyzed by the water-soluble Ru(II)-TPPTS (i.e., triphenylphosphine trisulfonate sodium) catalyst in capillary microreactors (made of polytetrafluoroethylene (PTFE); inner diameter: 0.50, 0.75 and $1.00 \mathrm{~mm}$ ), under elevated hydrogen partial pressures (1.0-2.0 $\mathrm{MPa}$, mitigated by Ar) and reaction temperatures (up to $90^{\circ} \mathrm{C}$ ). Determined by the hydrophobicity of the capillary material, the substrates (Fig. 3a, prenal, i.e., $\mathrm{R}_{1}=\mathrm{R}_{2}=$ $\mathrm{CH}_{3}$ and citral, i.e., $\mathrm{R}_{1}=\mathrm{CH}_{3}, \mathrm{R}_{2}=\mathrm{C}_{6} \mathrm{H}_{11}$ ) were disolved in nhexane or toluene as the continuous phase, where catalysts containing aqueous droplets and gas bubbles (of $\mathrm{H}_{2}$-Ar gaseous mixture) were alternatively dispersed via double $\mathrm{T}$ junctions at the microreactor inlet. Under the slug flow regime with small spherical bubbles and elongated aqueous droplets (Figs. $3 \mathrm{~b}$ and c), the specific liquid-liquid surface area was up to $769 \mathrm{~m}^{2} / \mathrm{m}^{3}$. Furthermore, the increase of the gas flow rate within $1.4 \mathrm{~mL} / \mathrm{min}$ benefited the reaction rate, since the number ratio between bubbles and droplets increased to around 1 (i.e., from the sub-regime (iii) changed to (i); cf. Fig. 1a). But a further increase of the gas flow rate led to a slight decrease of the reaction rate due to the insufficient liquid-liquid surface area and short residence time. Similarly, the increase of the aqueous (catalyst) flow rate also resulted in an increased reaction rate due to the enhanced liquid-liquid mass transfer. These results indicate that both the gas-liquid and liquid-liquid mass transfer resistances could be potentially eliminated by optimizing the flow pattern and total flow rates. Meanwhile, the substrate conversion was highly related to the residence time, which could be tuned through changing the length and inner diameter of the capillary microreactor or the flow rate of fluids. A relative low value of the activation energy at 32.3 $\pm 1.3 \mathrm{~kJ} / \mathrm{mol}$ was obtained under a nonoptimal condition, where the reaction rate might be still controlled by mass transfer rates due to the low solubility of substrates in the aqueous phase. Accordingly, they confirmed that the mass transfer limitation can be further removed by decreasing the inner diameter of the capillary microreactor, i.e., creating larger specific area and more intensive convective circulation. These results highlight the usefulness of microreactors as an effective tool for investigating kinetics of gas-liquid-liquid reactions, thanks to the accurate control over the slug flow regime and intensified mass transfer through interfaces.

\section{Heterogeneous catalysis}

Yap et al. [30] investigated the hydrogenation of various substrates (i.e., 1-hexene, cyclohexene, styrene, nitrobenzene and 4-nitrochlorobenzene; disolved in cyclohexane) to the corresponding alkanes (which are important for fuel and lubricating industries) in a PTFE capillary microreactor (inner diameter: $1 \mathrm{~mm}$ ) under ambient conditions, with aqueous droplets loaded with Rh nanoparticles (RhNPS; $0.5 \mathrm{mM}$ on the basis of Rh atoms) as the catalyst containing phase. Given a large excess of the gas phase (pure hydrogen; void fraction being 0.96 0.99 ) adopted in their system, relatively long gas bubbles were generated alternating with aqueous droplets (i.e., the subregime (i) as shown in Fig. 1a), providing a narrow continuous slug in between. The conversion of 1-hexene (cf. the reaction scheme in Fig. 4a) in the microreactor was found to decrease with the increase of the residence time (which was realized by decreasing the gas flow rate $Q_{G}$ ) under given liquid flow rates. This is explained by a significant widening of the continuous organic slug ( $W_{\text {org }}$ in Fig. $4 \mathrm{~b}$ ), which led to larger diffusion distances (i.e., the transfer of substrate/gas from the organic phase/bubbles to at least the aqueous-oil interface) and thus slower mass trasnfer rates (Fig. 4b). Though confined by the gas mass transfer through the organic slug, comparable substrate conversions and higher selectiveties towards target products were achieved within 10-100 times smaller residence time compared to its batch counterpart. Meanwhile, the catalyst activity (defined by moles of the converted substrate per mole of $\mathrm{Rh}$ atoms per minute) was 10-50 times higher than in batch under otherwise the same reaction conditions. For example, the hydrogenation of 4nitrochlorobenzene gave a conversion of $76 \%$, a selectivity of $89 \%$ towards 4-chloroaniline and a catalyst activity of $229 \mathrm{~min}^{-1}$ within $0.5 \mathrm{~min}$ in the capillary microreactor tested, while the corresponding results in batch were respectively $80 \%, 20 \%, 2 \mathrm{~min}^{-1}$ and $60 \mathrm{~min}$ [30]. More importantly, the confinement of solid nanoparticle catalysts within aqueous 
Fig. 3 Selective hydrogenation of $\alpha, \beta$-unsaturated aldehydes to unsaturated alcohols with aqueous catalyst (Ru(II)-TPPTS) in gas-liquid-liquid microreactors [29]. a Reaction scheme. b Schematic and $\mathbf{c}$ photo of gasliquid-liquid slug flow in the PTFE capillary microreactor (a)<smiles>[R2]C(C)=CC=C</smiles>

R1
$+\mathrm{H}_{2} \underset{\mathrm{H}_{2} \mathrm{O}, \text { solvent }}{\stackrel{\mathrm{Ru}(\mathrm{II}) \text {-TPPTS }}{\longrightarrow}}$

R1 (b)

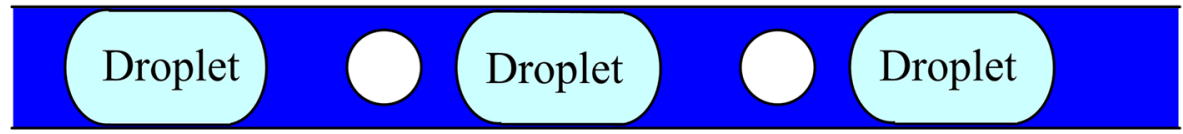
Aqueous phase $\square$ Gas phase $\square$ Organic phase

(c)

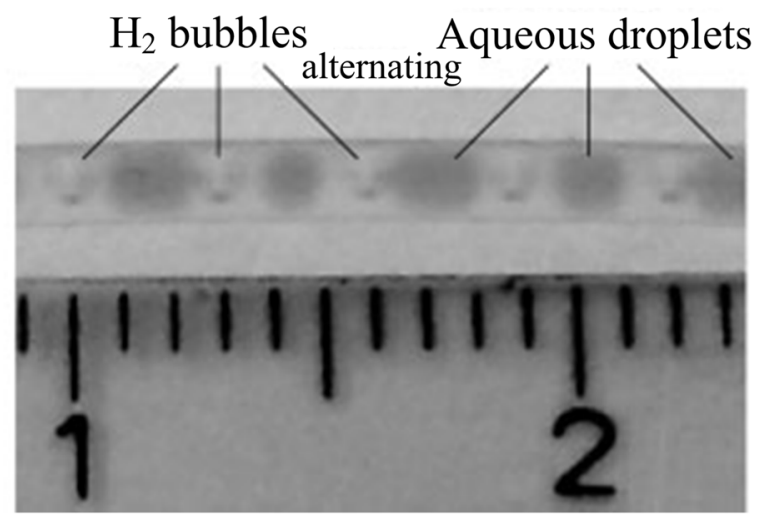

(a)

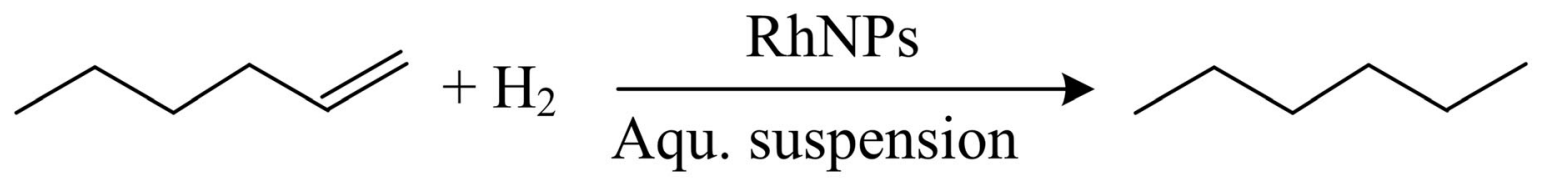

(b) Gas flow rate
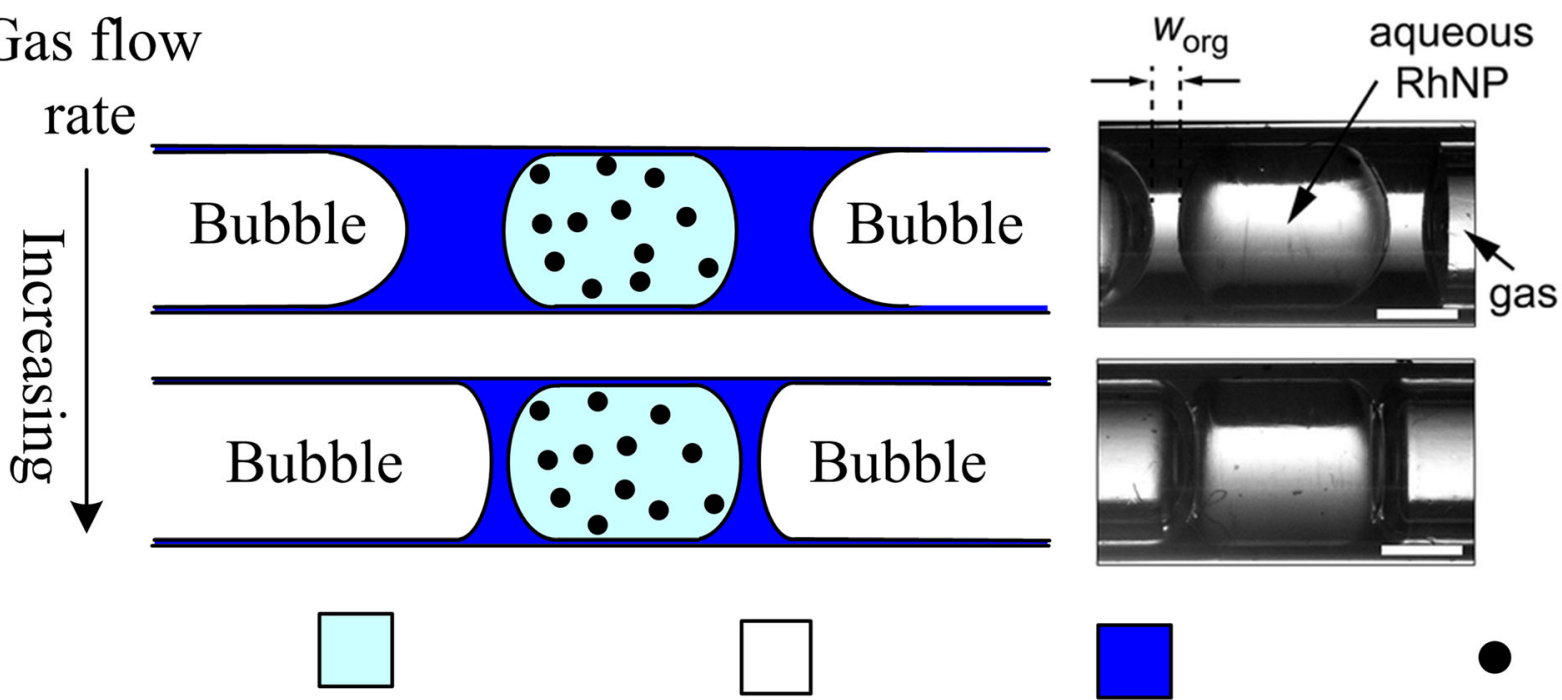

Aqueous phase

\section{Gas phase}

\section{Organic phase}

RhNPs

Fig. 4 Hydrogenation of various alkenes to the corresponding alkanes in gas-liquid-liquid microreactors [30]. a Reaction scheme for the hydrogenation of 1-hexene. b Schematics (left) and photos (right) of gas-liquid-liquid slug flow under large gas void fraction conditions 
droplets, largely circumvented the clogging risk in the microreactor. Meanwhile, the catalyst could be easily recycled by phase separation. This work has demonstrated not only the overall applealing performance of gas-liquid-liquid reactions in microreactors, but also a practical method to operate solid catalysts in microflow.

Karan and Khan [11] further tested the adaptability of the hydrogenation operation of Yap et al. [30] in a relatively large diameter capillary microreactor (inner diameter: $3.2 \mathrm{~mm}$ ), in order to increase the productivity. Under similar operating conditions (e.g., flow pattern, gaseous sources and void fraction), the hydrogenation of 1-hexene (0.8-2.4 M; in decane) catalysed by rhodium nanoparticles immoblized in the aqueous phase was investigated. A shift of the apparent reaction order from zero to first order behavior when lowering the initial substrate concentration was observed, which was considered to be caused by the insufficient supply of 1-hexene to the aqueous-organic interface especially under low initial concentrations of 1-hexene and long residence times. Nevertheless, the overall performance in such large capillaries (e.g., a full conversion was reached within $2 \mathrm{~min}$ ) was still highly intensified compared to its batch counterpart (with a full conversion within $60 \mathrm{~min}$ ). These results indicate that the basic process intensification characteristics are transferable when increasing the capillary diameter from 1 to $3.2 \mathrm{~mm}$, except for a more prominent limitation of the mass transport of 1-hexene to the aqueous-organic interface. More importantly, such a single capillary (i.e., with an inner diameter of $3.2 \mathrm{~mm}$ ) can produce up to $120 \mathrm{~g}$ hexane per day, which is a dramatic improvement over the limited throughput in the $1 \mathrm{~mm}$ diameter capillary microreactor (being $0.8 \mathrm{~g}$ hexane per day [11]).

In conclusion, it seems that the overall performance of gasliquid-liquid reactions tested in microreactors is still limited by gas-liquid or liquid-liquid mass transfer, though a significant intensification was present compared with their macroscale counterpart. To eliminate the mass transfer resistance, the microreactor diameter can be further reduced, which also leads to a lower production throughput. The hydrogenation reactions mentioned above [11, 29,30] occurred in the bulk of the dispersed aqueous droplets (Fig. 4b), which makes the whole mass transfer scenarios more complicated, especially for the gas transfer to the aqueous bulk (i.e., subsequently through the gas-oil interface, organic bulk, aqueous-oil interface and aqueous bulk). In a most recent work, Liu et al. [12] revealed that the film flow through the gap between bubbles and the microchannel wall contributed significantly to the gas transferring into the continuous phase, and an alternating bubble/droplet sub-regime (Fig. 1a (i)) is preferred towards mass transfer optimization. For a more in-depth understanding into the effect of each transfer step on the overall reaction performance, various gas-liquid-liquid (model) reactions that take place at the gas-liquid interface (e.g., hydroformylation of olefins and styrene, carbonylation of benzylchloride and azadienes) and liquid-liquid interface (e.g., ozonation of methyl linoleate) [2] can be investigated separately in microreactors. More fundamentally, the effect of physical properties of the inactive catalyst carrier fluid on mass transfer $[57,58]$ and the effect of (homogeneous or heterogeneous) catalyst distribution within droplets on the reaction performance [35] should be studied in order to further clarify the limiting step in mass transfer, and to provide a better guidance towards the microreactor design and operation (e.g., choices of the continuous phase and slug length, etc.).

\section{Reaction-extraction coupling}

The reaction-extraction coupling process, namely the integration of reaction with the in-situ liquid-liquid extraction into a single operating unit, can enable a simultaneous separation of the target product(s). This process integration is capable of boosting the yield of the target product(s), e.g., by either preventing its successive reactions or bypassing the equilibrium limitations, and has the economic benefits due to the simplified equipment setup. Thus, this coupling process has attracted increasing attention in recent decades [16, 59-61] in both conventional reactors and microreactors, where in most cases only two immiscible phases are involved (i.e., one reactive phase and another extractive phase). For example, Guo et al. [16] synthesized 5-hydroxymethylfurfural (HMF; a promising platform chemical towards manufacturing potential biobased fuels and chemicals) from the aqueous glucose solution containing $\mathrm{AlCl}_{3}$ and $\mathrm{HCl}$ as the combined homogeneous catalysts, and the formed HMF was simultaneously extracted into methyl isobutyl ketone (MIBK) under liquidliquid slug flow operation in a capillary microreactor. This operation gave a higher HMF yield via suppressing the successive HMF-involved reactions (e.g., rehydration, degradation and/or polymerization). A third gas phase may be further included in some complex situations, such as the coupling of a gas-liquid reaction and the simultaneous liquid-liquid extraction of the target product(s). A typical example herein is the production of hydrogen peroxide, an environmental benign and effective oxidant that has been extensively used in various chemical processes (e.g., bleaching and wastewater treatment) [62].

Hydrogen peroxide is most commonly synthesized via the anthraquinone method. The full procedure of this routine in industry is shown in Fig. 5. The substrates, 2-ethyl-9,10-anthraquinone (EA Q) and tetrahydro 2 ethyltetrahydroanthraquinone (THEAQ), are first hydrogenated in the presence of $\mathrm{Pd} / \mathrm{Ni}$ catalysts to the corresponding anthrahydroquinone (i.e., $\mathrm{EAQH}_{2}$ and $\mathrm{THEAQH}_{2}$ ), which are successively oxidized by oxygen or air to EAQ and THEAQ, producing hydrogen peroxide. The working solution is sent to the extraction section with water, producing the 


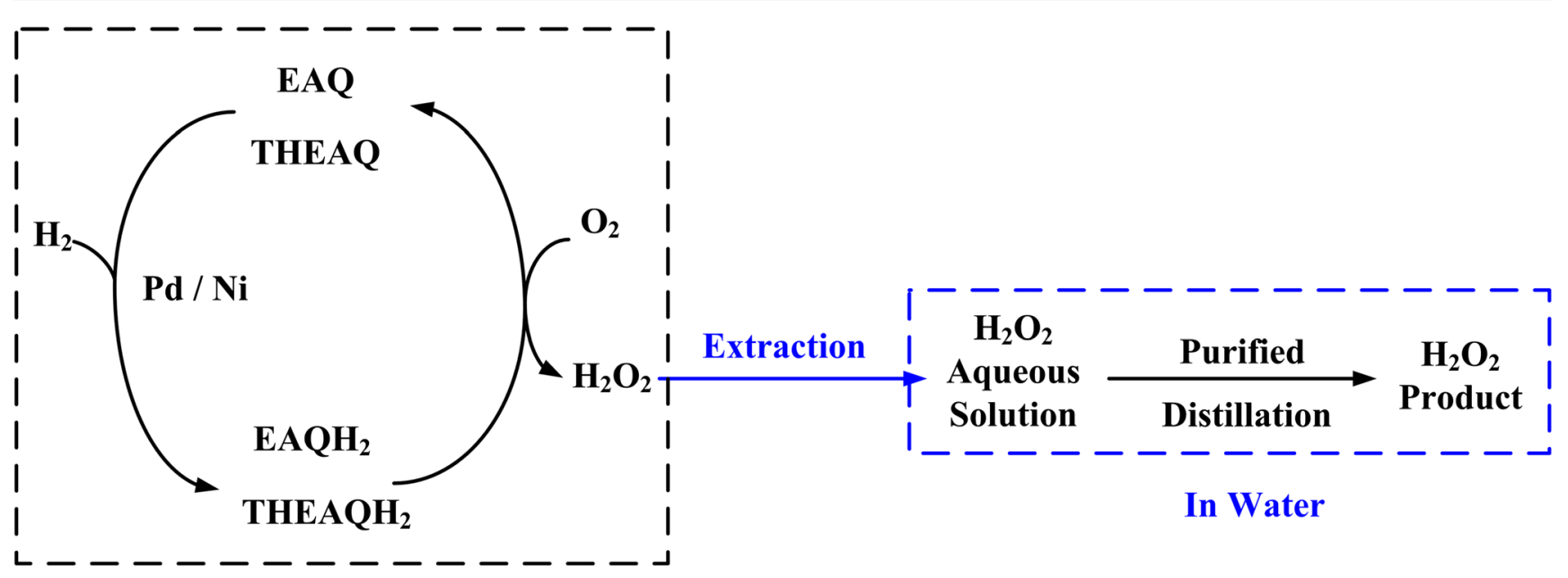

\section{In Working Solution}

Fig. 5 Industrial synthesis of hydrogen peroxide through the anthraquinone method. (Scheme adapted from the work of Tan et al. [65])

aqueous hydrogen peroxide solution to be further purified. The gas-liquid oxidation process is more preferable to be coupled with the liquid-liquid extraction process, due to their close operating conditions (e.g., both applicable within 40$70{ }^{\circ} \mathrm{C}$ ). The coupling process operated in conventional reactors (e.g., sieve plate column) showed that the three-phase system did not present an appreciable impact on the gasliquid reaction performance [59,60], but obviously facilitated the extraction efficiency. This implies that the extraction efficiency has a great potential to be enhanced by operating the coupling process in microreactors. Meanwhile, the oxidation reaction rate and the substrate conversion are also possible to improve in microreactors, since this reaction is considered kinetically fast compared to the gas-liquid mass transfer rate $[63,64]$. For example, in a gas-liquid two-phase membrane (pore size: $5 \mu \mathrm{m}$ ) microreactor using pure oxygen as oxidant without extraction coupling [21], a THEAQH ${ }_{2}$ conversion of $99.5 \%$ was achieved in $15 \mathrm{~s}$, while the conventional reactor would need tens of minutes to reach a similar conversion [65].

Tan et al. [21] investigated the coupling between the gasliquid oxidation and the extraction step for $\mathrm{H}_{2} \mathrm{O}_{2}$ production in microreactors. In more detail, the gas phase, organic substrate and water were first dispersed through two membrane dispersion modules (pore size: $5 \mu \mathrm{m}$ ) into a stainless steel capillary (inner diameter: $2 \mathrm{~mm}$ ) that served as the main microreactor, where both bubbles and droplets were of very small diameters on a magnitude of $100 \mu \mathrm{m}$. Two membrane dispersion modules were adopted in their work: 1) In non-in-situ module (upper image in Fig. 6a), the gas phase was first dispersed into the organic phase through the first membrane, then the gas-liquid mixture was dispersed into water phase (which served as the continuous phase in the main capillary microreactor) through the second membrane, resulting in the presence of discrete bubbles, droplets and double emulsions $(\mathrm{G} / \mathrm{O} / \mathrm{W})$ in the main capillary microreactor (upper image in Fig. 6b). Note that this flow pattern is different from a typical three-phase slug flow (e.g., the subregime (i) as shown in Fig. 1a), since the size of bubbles and droplets here are much smaller than the capillary microreactor diameter. 2) In in-situ module (lower image in Fig. 6a), the organic phase was dispersed into the previously formed gas-water mixture, resulting in discrete bubbles and droplets present in the microreactor (lower image in Fig. 6b). Both dispersion scenarios led to higher substrate conversions within much shorter residence times compared with the conventional counterpart. In the capillary microreactor, the extraction efficiency in the coupling process was significantly improved, in accordance with the fact that liquid-liquid mass transfer coefficients under gas agitation can be two folds higher than those in liquid-liquid two-phase systems [39]. However, the substrate conversion (i.e., in the oxidation reaction) in the microreactor did not show noticeable difference between with and without coupling. This might be because the gas-liquid mass transfer rate in the microreactor is already fast enough compared to the oxidation reaction kinetics.

From the aspect of mass transport in such reaction-extraction coupling process, the $\mathrm{G} / \mathrm{O} / \mathrm{W}$ emulsions from the non-in-situ mode (upper image in Fig. 6b) are expected to enhance both the gas-liquid and liquid-liquid mass transfer more than the case with individually dispersed bubbles and droplets (lower image in Fig. 6b), because the double emulsion structure not only enables the direct gas-oil contact, but also largely increased the water-oil interfacial area given a fixed oil volume. In fact, the overall liquid-liquid mass transfer coefficients of the double emulsion structure have been theoretically and experimentally proved to be as much as two orders of magnitude higher than those of the separately dispersed droplets $[21,41,43,66]$. However, no predominant difference in the extraction efficiency was found between these two dispersion scenarios (Fig. 6b), which might be because of a very small fraction (not determined in the current literature) of the double emulsions in the non-in-situ mode (upper images in Fig. 6a and b). Alternatively, other flow configurations 
Fig. 6 Reaction-extraction coupling for $\mathrm{H}_{2} \mathrm{O}_{2}$ production in gas-liquid-liquid microreactors. a Configurations of membrane dispersion modules [21]. b Photos of bubbles and droplets in the stainless steel capillary microreactor [21] (left) and the corresponding schematic view of the microreactor cross section (right; where red arrows refer to the double emulsion structures in the continuous phase). c Alternative flow configurations in gas-liquidliquid slug flow in the microreactor (a)

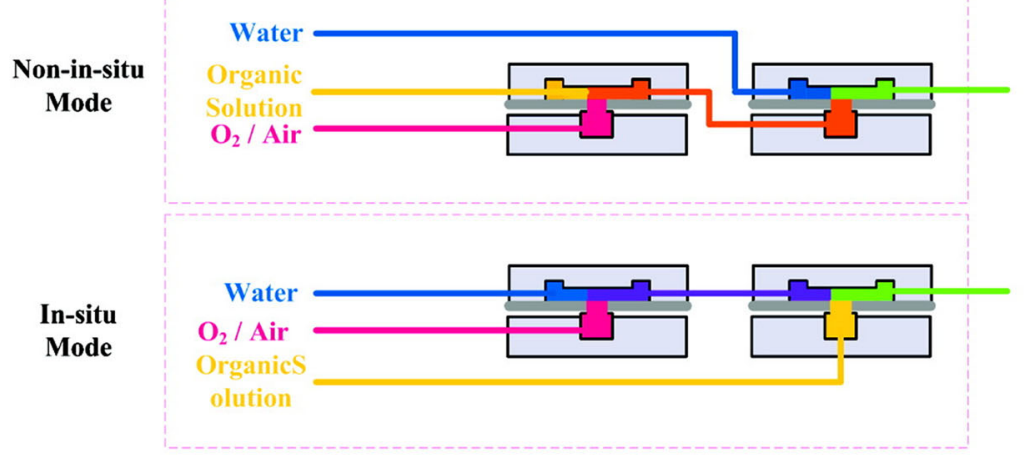

(b)
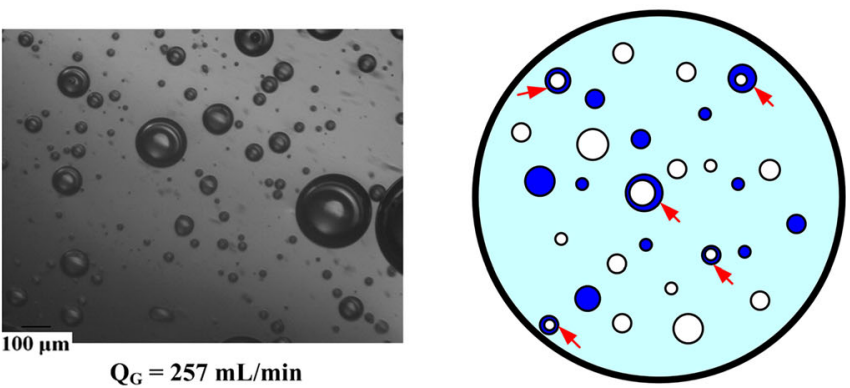

\section{Non-in-situ Coupling mode}

$$
\mathrm{Q}_{\mathrm{G}}=257 \mathrm{~mL} / \mathrm{min}
$$

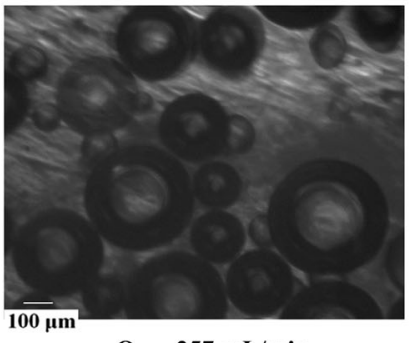

$Q_{\mathrm{G}}=257 \mathrm{~mL} / \mathrm{min}$

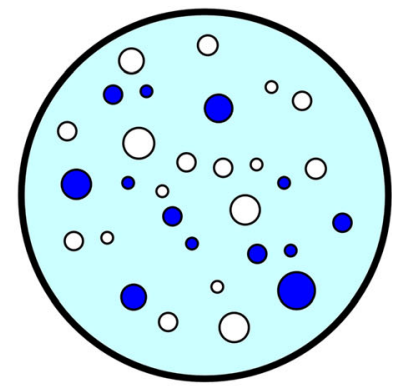

(c) $(\mathrm{G}-\mathrm{W}) / \mathrm{O}$

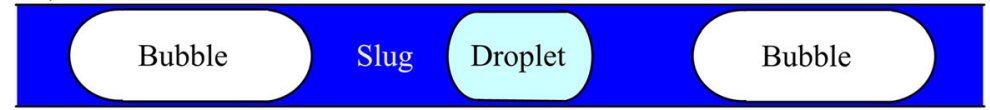

$\mathrm{G} / \mathrm{O} / \mathrm{W}$

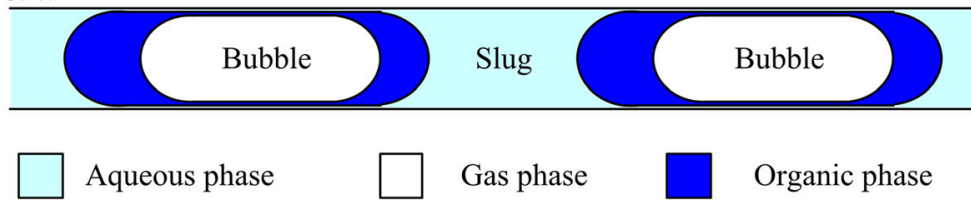

under gas-liquid-liquid slug flow could be designed in the microreactor to provide a direct gas-oil and water-oil contact, such as separately dispersed bubbles and aqueous droplets in the continuous organic phase $((\mathrm{G}-\mathrm{W}) / \mathrm{O}$ in Fig. 6c) $[13,14,50$, 52] and double emulsions $(\mathrm{G} / \mathrm{O} / \mathrm{W}$ in Fig. 6c) [17]. Thus, the sizes of all segments (bubbles, droplets and continuous slugs) and the specific (gas-liquid or liquid-liquid) interfacial areas are able to be precisely controlled, e.g., by tuning flow rates, materials and dimensions of microreactors, inlet micromixer types and fluid delivering sequences [13, 18, 49, 50]. These would allow to achieve a more predictable and/or better process performance.

\section{Inert gas assisted liquid-liquid reactions}

The presence of inert gas bubbles in an otherwise liquid-liquid system can largely enhance the liquid-liquid mass transfer rate (e.g., up to several orders of magnitude higher [22, 41, 43, 
66]) via either the additional agitation that intensifies the convective circulation [40] or the enlargement of the specific interfacial area. It also plays an important role in helping to maintain the regular liquid-liquid contact pattern (e.g., by preventing the droplet coalescence), which is crucial for the system performance reproducibility and interpretation as well as kinetic studies [29]. Thus, the addition of an inert gas can enhance the liquid-liquid reaction performance that is usually limited by the interfacial mass transfer if the reaction kinetics are fast enough, and has potential to be applied in microreactors. Furthermore, adding an inert gas into a liquid-liquid flow in microreactors can lead to a beneficial flow pattern change. For example, liquid-liquid systems in microreactors usually tend to form parallel flow under relatively large flow rates, which significantly reduces the interfacial area compared to slug flow. After introducing the inert gas, the shear force exerted by the gas bubbles could force the parallel flow to break into separate droplets, and thus a stable gas-liquid-liquid slug flow could be obtained under relatively higher total liquid flow rates [52].

Another hydrodynamic function of the inert gas addition is to prevent droplet merging in microreactors [32, 67]. For example, Cech et al. [32] conducted the enzymatic hydrolysis of soybean oil to biodiesel in PTFE capillary microreactors (inner diameter: 0.5 and $0.75 \mathrm{~mm}$ ), by dispersing the aqueous solution containing $T$. lanuginosus lipase and phosphate buffer as small droplets into the crude soybean oil as the continuous carrier. The enzymatic reaction occurred at the liquid-liquid interface, where the chemical compositions and interfacial properties changed during the course of the reaction, leading to unstable liquid-liquid interfaces. As a result, severe droplet coalescence took place at the outlet of the microreactor when performing reaction in the liquid-liquid two-phase system (Fig. 7). The addition of an inert gas (i.e., nitrogen) limited the droplet coalescence within the space between the adjacent bubbles, and therefore provided a stable uniform flow pattern through the microchannel (Fig. 7). Besides, the availability of the aqueous-oil interface was increased in three-phase flow compared to its two-phase counterpart, because droplets appeared to be smaller in three-phase flow (which enabled a large oil flow rate between the droplet and the channel wall). This, plus the agitation of gas bubbles, created intensive convection in the liquid region over the whole droplet interface. As a result, the gas-liquid-liquid three-phase flow operation in the microreactor yielded comparable or even better conversions than its liquid-liquid counterpart, though the residence time was substantially reduced. Moreover, the presence of gas bubbles was found to facilitate the temperature-sensitive reactions towards achieving higher reaction conversions and selectivities. Zhang et al. [36] performed the Beckmann rearrangement of cyclohexanone oxime in oleum (an important step in manufacturing $\varepsilon$ - caprolactam as the monomer of nylon-6) in a PTFE capillary microreactor (inner diameter: $1.8 \mathrm{~mm}$ ) coupled with an inlet micromixer. The reaction was performed using cyclohexanone oxime dissolved in n-octane as the continuous phase with oleum and nitrogen (if present) as the dispersed phase. Due to the strongly exothermic nature of the reaction, side reactions like carbonization are easily triggered resulting in local hotspots. An obvious increase of the target product (i.e., $\varepsilon$-caprolactam) was observed after the gas addition into the original liquid-liquid system in the microreactor, because bubbles created a large evaporation space to take away the reaction heat. This results in an evener temperature distribution and more uniform rearrangement mixtures among unit cells, which in turn yielded narrowed viscosity distribution (Fig. 8a) and less droplet coalescence (Fig. 8b). Meanwhile, the overall liquid-liquid mass transfer rate was accelerated by 1.5-3.8 times in three-phase microflow compared to the twophase system, which further improved the reaction performance.

It should be noted that the addition of an inert gas does not always lead to a regular three-phase flow regime, mass/heat transfer intensification or better reaction performance. Aoki et al. [52] demonstrated that three-phase flow tended to be unstable under too low gas void fractions, and an optimum void fraction of 0.1 was proposed under their operating conditions. Assmann et al. [40] reported that no noticeable mass transfer intensification was observed under low gas velocities $(<0.08 \mathrm{~m} / \mathrm{s})$ in a microchannel $(0.3 \mathrm{~mm}$ in width), and the liquid-liquid extraction results were comparable in both three-phase and two-phase microflows at residence times on the magnitude of seconds. This is because bubbles were tightly attached to droplets (Fig. 9a) in their flow pattern, which largely limited the motion space of bubbles and thus the agitation effect. Interestingly, even if initially discrete bubbles and droplets were present (Fig. 9b (1)), they usually ended up with bubble-droplet clusters (Fig. 9b (2), named according to the arrangement of bubbles/droplets along the flow direction) or droplet-bubble clusters (Fig. 9b (3)) after collision along the microchannel. Considering the positive correlation between the motion velocity of bubbles/droplets and the capillary number $[68,69]$, one may expect that droplets move faster than bubbles (due to usually a lower liquidliquid interfacial tension compared to that for gas-liquid case) and thus droplet-bubble clusters are expected to be more prevalent. However, the bubble/droplet collision configurations are subject to other factors as well, such as channel materials, flow ratios, bubble/droplet generation mechanisms and surfactant concentrations [70-72]. In fact, bubbledroplet clusters were also observed in many cases [12, 52, 70]. The draining of the continuous phase between bubbles and droplets often leads to flattened droplet caps (Fig. 9b) $[14,49]$, which may disable the bubble/droplet caps from reaction if the continuous phase was reactive and totally 
Fig. 7 Liquid-liquid interfacial areas (denoted as $a$ in the figure) and phase dispersions at the inlet and outlet of a capillary microreactor, without and with inert gas addition [32]

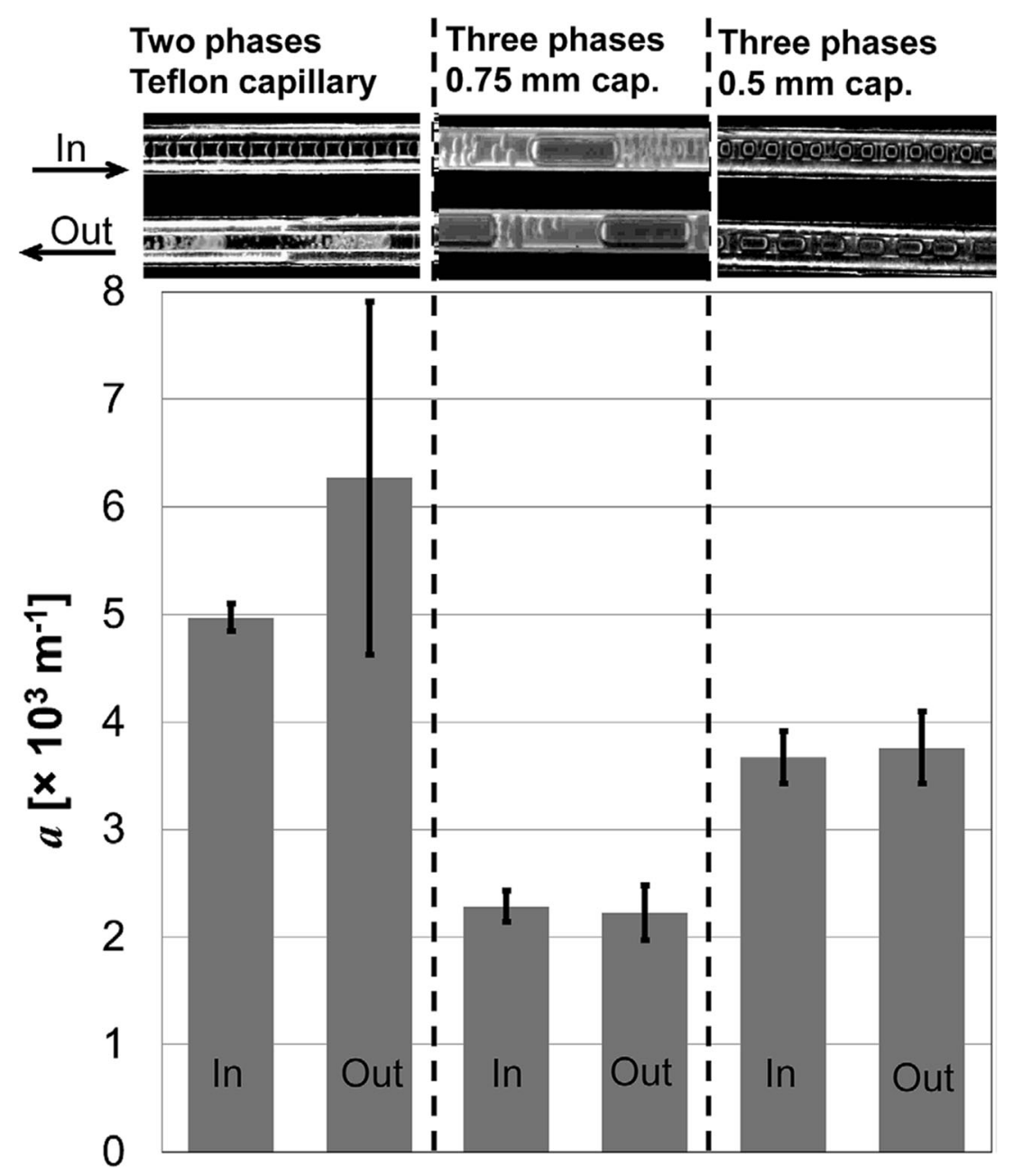

drained out. The effect of the bubble-droplet cluster configuration on the reaction performance was demonstrated by Ufer et al. [35], who carried out the catalytic transfer hydrogenation of m-nitrotoluene to $\mathrm{m}$-toluidine in a $20 \mathrm{~m}$ long capillary microreactor (inner diameter: $1.6 \mathrm{~mm}$ ). The aqueous potassium formate solution (hydrogen source) was dispersed in the continuous toluene phase containing the dissolved substrate nitrotoluene. $10 \mathrm{wt} . \%$ palladium on carbon (a)

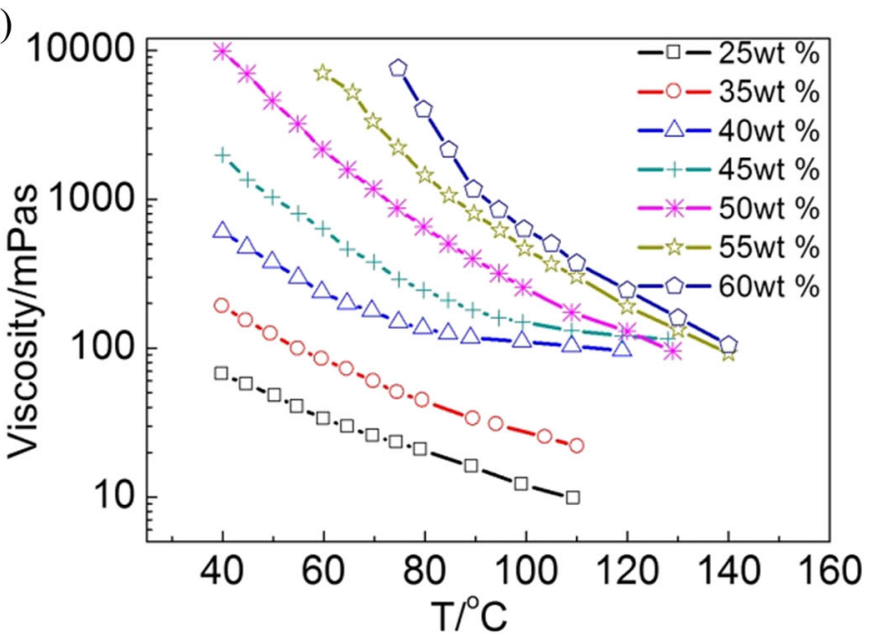

(b)

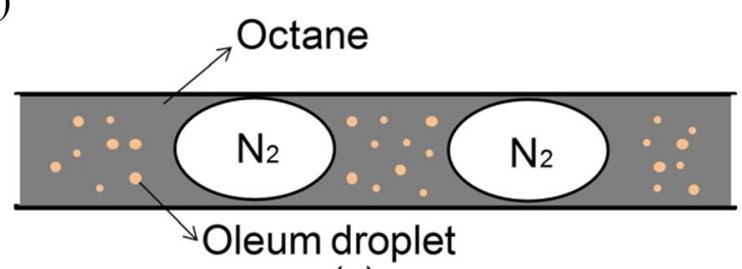

(a)

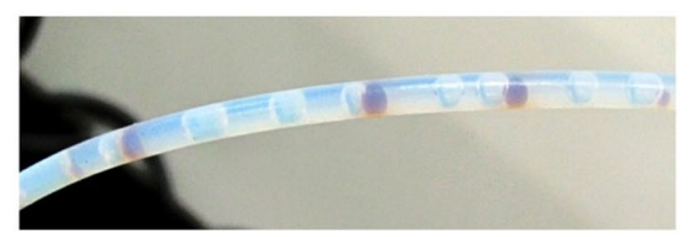

Fig. 8 Beckmann rearrangement of cyclohexanone oxime with inert gas agitation in a PTFE capillary microreactor [36]. a Viscosity of rearrangement mixtures. b Schematic (upper) and photo (lower) of the three-phase flow pattern in the microreactor 
Fig. 9 Schematics of the relative positions between bubbles and droplets in gas-liquid-liquid slug flow. a Tightly attached bubbles/ droplets. In b, the sub-figure (1) represents discrete bubbles/ droplets as well as its possible collision configuration, the subfigure (2) is for bubble-droplet clusters and (3) droplet-bubble clusters. The fluids flow from left to right, and the $\mathrm{Pd} / \mathrm{C}$ catalyst particle distribution in the continuous phase refers to the work of Ufer et al. [35]. c Conversion of $\mathrm{m}$-nitrotoluene in gas-liquidliquid slug flow with different collision configurations [35] (a) Tightly attached bubbles and droplets

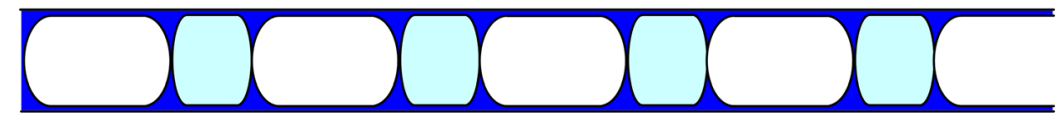

(b) Discrete bubbles and droplets

(1) Initial state

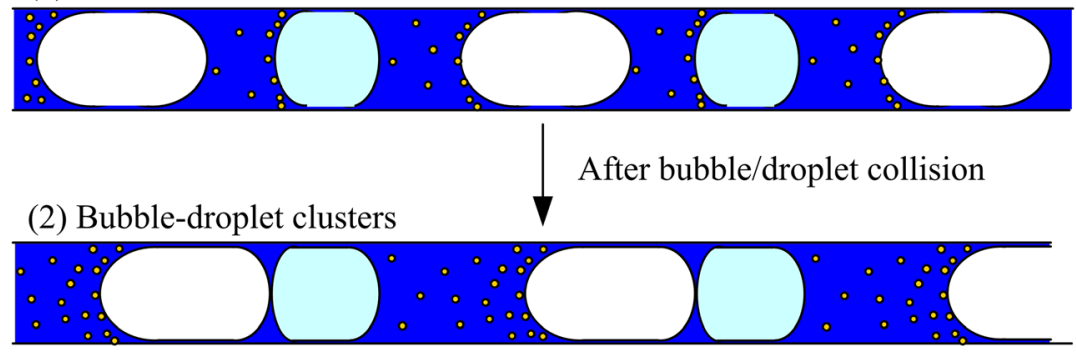

(3) Droplet-bubble clusters

Or

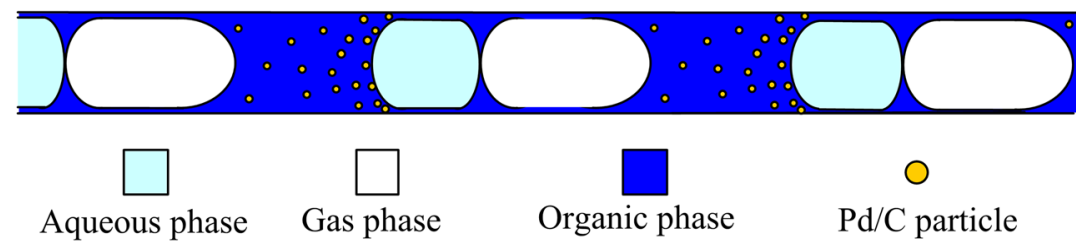

(c) Substrate conversion under different collision configurations

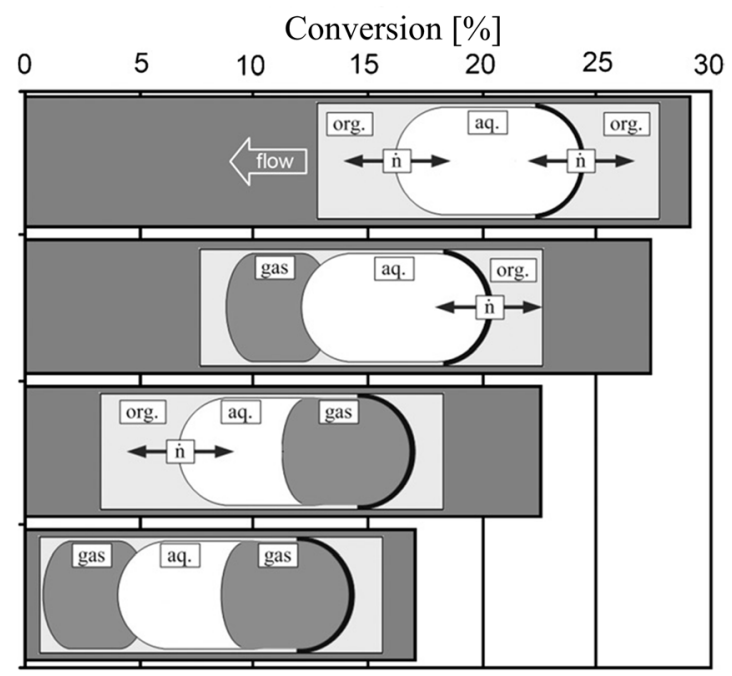

particles were suspended in the organic phase as catalyst. After adding nitrogen bubbles, the substrate conversion was surprisingly decreased compared to the liquid-liquid operation, with residence times ranging from 15 to $35 \mathrm{~min}$. More importantly, the reduction in the substrate conversion under three-phase slug flow with bubble-droplet clusters was much higher than that with droplet-bubble clusters (Fig. 9c). This is because catalytic particles mainly aggregated at the rear cap of droplets (observed in the liquid-liquid two-phase microflow). According to this, the catalyst distribution with gas addition (i.e., three-phase flow) was proposed as shown in Fig. 9b. When bubble-droplet clusters were formed (Fig.
$9 \mathrm{~b}(2))$, the catalyst concentration around the rear end of the aqueous droplet was evidently reduced, while that around the front end was already relatively low. As a result, the corresponding reaction performance was largely decreased (Fig. $9 \mathrm{c}$, the third entry). However, in the case of droplet-bubble clusters, the rear end of droplets were still exposed to highly concentrated catalysts (Fig. 9b (3)), which led to a higher conversion (Fig. 9c, the second entry) than that in the former case. These results highlight the significance of bubbledroplet collision configurations on the mass transfer and reaction performance in three-phase microflow, and thus deserves much research attention. 


\section{Nanoparticle synthesis}

Solid handling is usually a challenge in a microreactor that is susceptible to clogging because of the small dimension. This problem can be well addressed by isolating the solid from the microchannel wall via its accommodation into droplets, and further using bubbles to separate droplets thus avoiding droplet merging and solid aggregation [11, 30]. Furthermore, bubbles can also function as an excellent mitigator in mixing the designated fluids. The latter has been shown to be crucial in processes when a stepwise mixing of homogeneous solutions is need (e.g., in the preparation of palladium nanoparticles (PdNPs) [37]), and when the regents need to be mixed in the same droplet instead of creating a new droplet in the course of injection [38]. However, the creation of a new droplet is strongly subjected to bubbles from the upstream flow $[13,14,72$, 73]. As shown in Fig. 10a, when the upstream bubble is too long, a new droplet of the injected liquid feed will be formed between two daughter bubbles of non-uniform sizes. When bubbles are too small and the continuous phase slugs are too long, extra free-ruptured droplets would be generated (Fig. 10c) [14, 49, 50]. Only when the droplets are cut off by gas-liquid interface (i.e., alternate and uniform bubbles and droplets can be formed downstream, as shown in Fig. 10b) [14, 49, 50, 73], new droplet formation will be avoided. In this way, a precise mixing during multistep injections is possible (Figs. 11ab). Following this principle, Wong et al. [37] achieved a $\sim 10$ L per day volumetric productivity of catalytically ac-

\section{(a) Cut by bubble body}

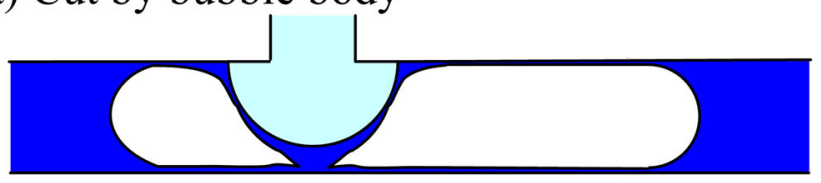

(b) Cut by gas-oil interface

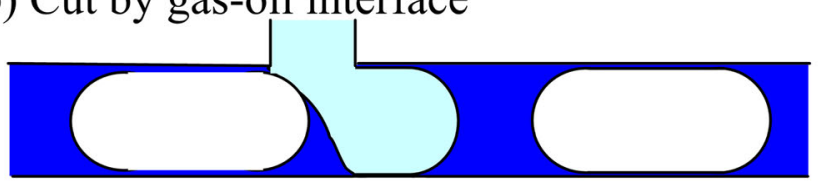

(c) Squeezed by continuous phase

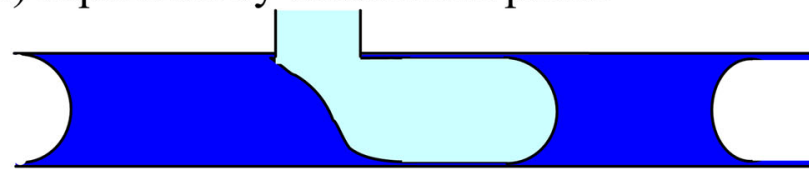

\section{Aqueous phase}

Fig. 10 Three droplet formation mechanisms at a T-junction under the oil-gas-water (O-G-W) fluid injection sequence. Droplets could be cut off by $\mathbf{a}$ the bubble body and $\mathbf{b}$ the gas-oil interface, or $\mathbf{c}$ squeezed off by the tive PdNPs in a single capillary microreactor, with a robust and continuous operation. They first dispersed the Pd precursor solution as droplets into a carrier phase (fluorinated oil), then separated the droplets by the addition of $\mathrm{N}_{2}$ bubbles, and finally mixed a newly fed $\mathrm{NaBH}_{4}$ solution with the previous droplets (Fig. 11c). This mixing part was realized in a small capillary (inner diameter: $0.5 \mathrm{~mm}$ ) for the sake of controllability over a fine dispersion, after which the fluids were introduced into a larger capillary (inner diameter: $1.6 \mathrm{~mm}$ ) for precipitation. The PdNPs synthesized in the gas-liquid-liquid microreactor system presented not only a smaller mean size $(2.3 \pm 0.3 \mathrm{~nm})$ compared with the batch counterpart $(3.4 \pm 0.9 \mathrm{~nm})$, but also a narrower particle size distribution. Besides, the synthesized PdNPs in three-phase microflow showed a better consistency towards particle size after 6-h run during 1hexene hydrogenation under triphasic flow, and higher catalytic activities (substrate conversion of $77 \%$ vs. $48 \%$ for batch-synthesized particles). This work highlights the appealing controllability of gas-liquid-liquid microreactors in phase dispersion and promising applications in solidinvolving processes $[53,74]$. Besides, gas-liquid-liquid microreactors also serve as a promising tool for nanoparticle synthesis with gas-liquid reactions, such as using $\mathrm{CO}$ reactive gas to reduce precursors and form Pt nanoparticles in aqueous droplets that are dispersed in a continuous oil phase [44]. In addition, hollow particles were also frequently synthesized in microreactors, but usually with sophisticated flow-focusing devices (interested readers are referred to the recent review of Chen et al. [19]).
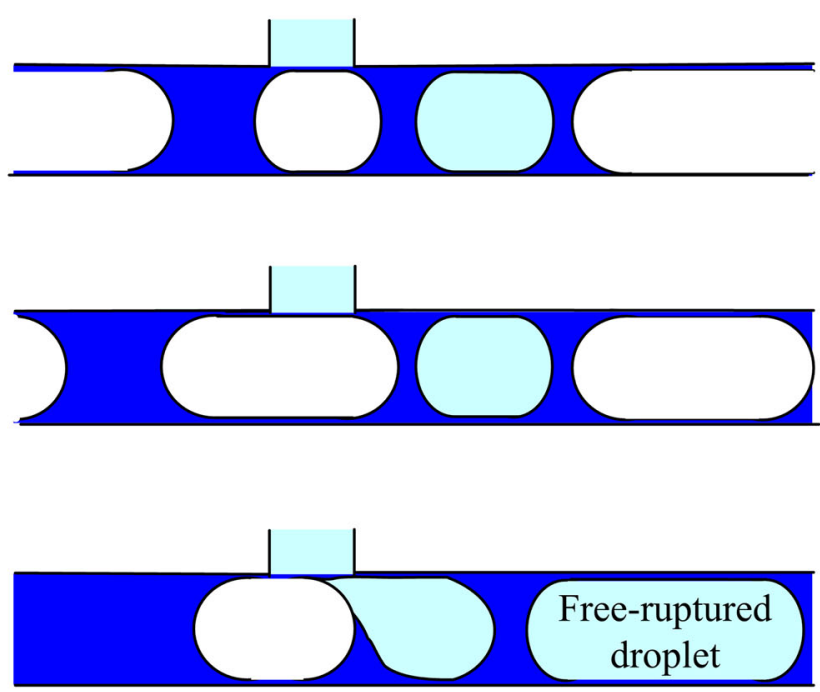

\section{Gas phase $\square$ Organic phase}

continuous phase [14]. In a-c, the left sketches develop into the right ones after a certain time interval 
Fig. 11 Direct injection of reagents into droplets within gasliquid-liquid slug flow in the microreactor. a Schematic and $\mathbf{b}$ a sequence of photos showing the principle according to the work of Nightingale et al. [38]. c The application in the synthesis of PdNPs [37] (a)

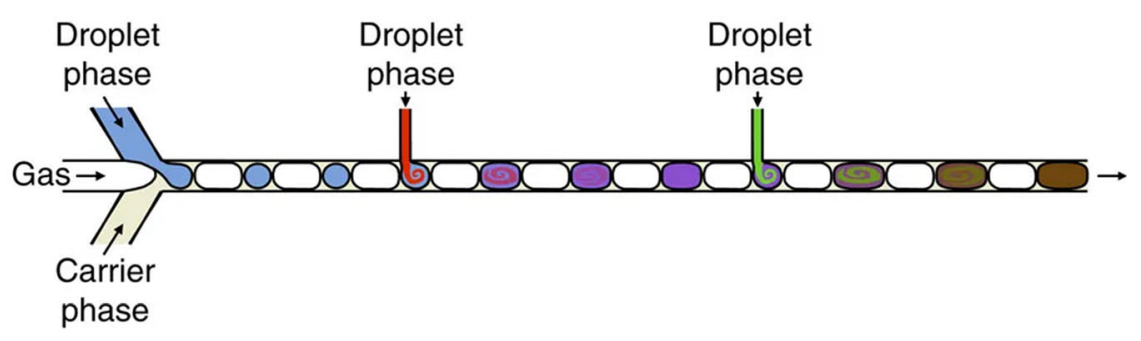

(b)
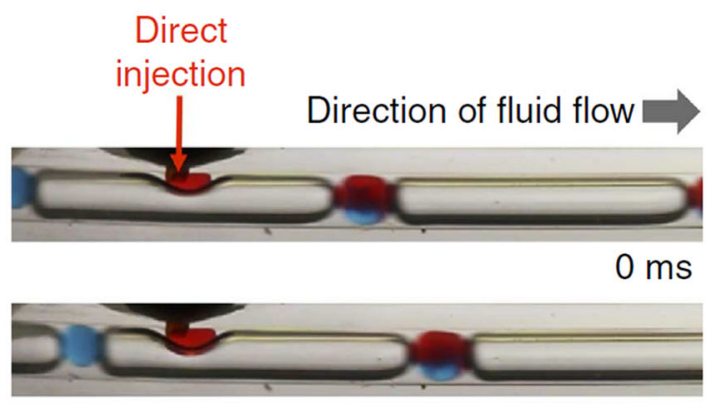

$120 \mathrm{~ms}$

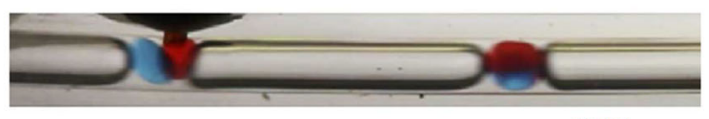

$240 \mathrm{~ms}$
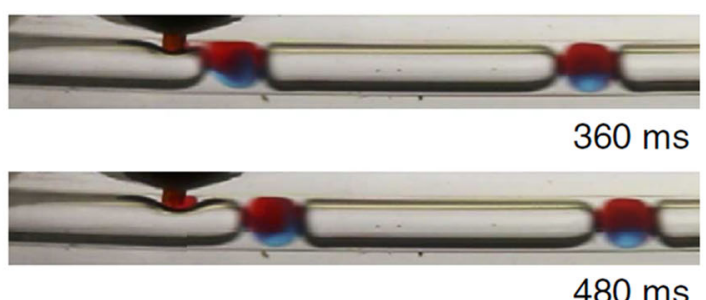

(c)

$480 \mathrm{~ms}$

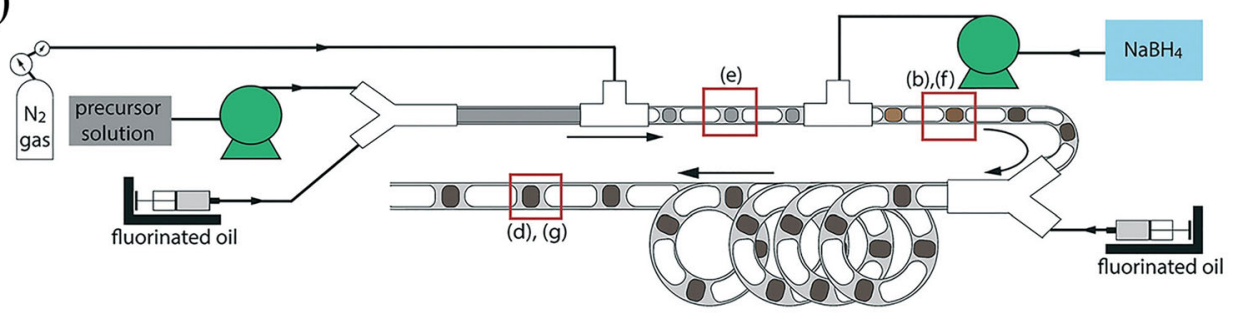

\section{Future perspectives}

Scale-up methods have been developed to narrow the gap between the limited throughput in a single microreactor unit and the production need in the industry. Numbering up via a simple replication of basic microreactor units is the most known scale-up strategy. When it comes to gas-liquid-liquid flow, Yap et al. [31] have developed an 8-fold parallelized network for the continuous hydrogenation of nitrobenzene (catalyzed by platinum nanoparticles: PtNPs) under threephase slug flow in capillary microreactors. In this network, regents were respectively distributed into 8 identical branches, and then mixed by T-junctions into each single microchannel where the reaction took place. An $R_{1}-C-R_{2}$ schema $\left(R_{1}\right.$ represents a narrow diameter tube with rigid walls as the fluidic resistor, $\mathrm{C}$ is a relatively large diameter tube with flexible walls as the fluidic capacitor, $\mathrm{R}_{2}$ stands for all channels at the downstream of the fluidic capacitor; see Fig. 12a) was used to stabilize the pressure and flow fluctuations caused by periodic bubble/droplet generation into the reaction microchannel. An optimized performance was obtained when the flow resistance of $\mathrm{R}_{1}$ equals to that of the capillary section $\mathrm{R}_{2}$. With an extra pump and a reservoir, the network realized the complete online recovery and recycle of the catalyst (Fig. 12b). Besides, Karan and Khan [11] demonstrated that by increasing the inner diameter of the capillary microreactor, mass transfer rate could be still reasonably intensified and the throughput of a single microreactor unit could be substantially raised (e.g., up 


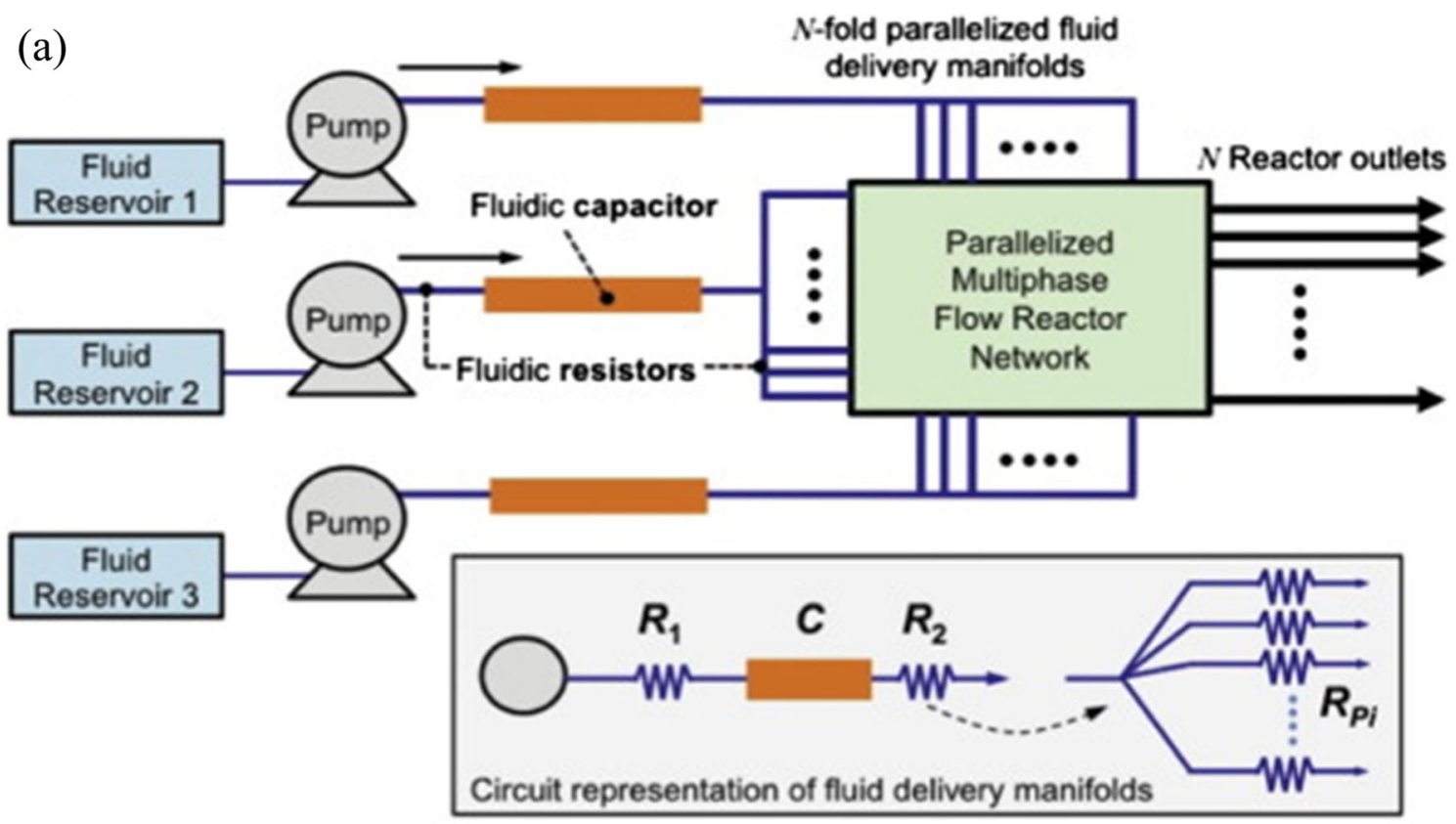

(b)

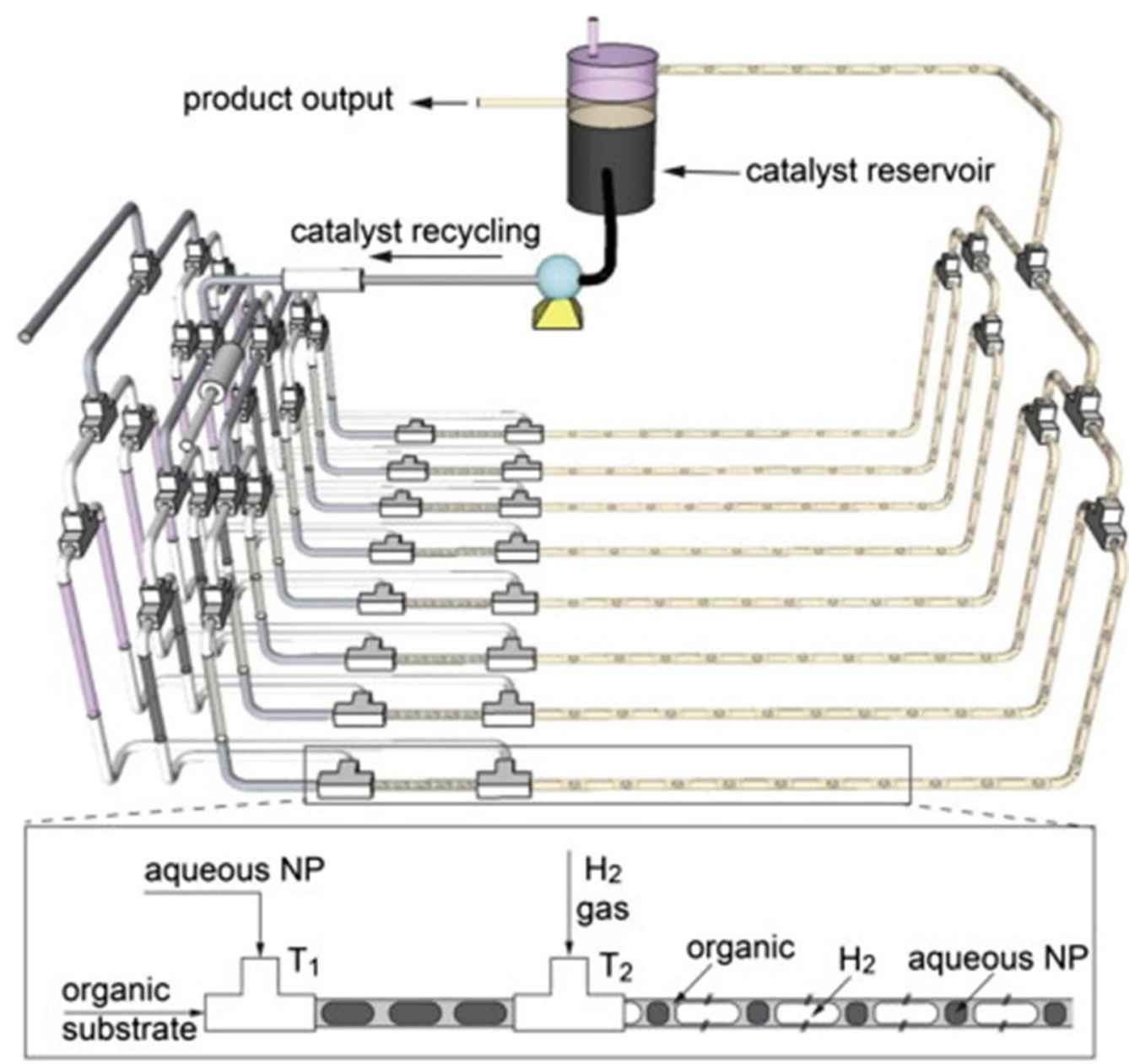

Fig. 12 Scale-up of gas-liquid-liquid microreactors for nanoparticlecatalyzed hydrogenations [31]. a The $\mathrm{R}_{1}-\mathrm{C}-\mathrm{R}_{2}$ schema to stabilize gasliquid-liquid there-phase flow from fluctuations. b Schematic of the triphasic flow microreactor system for continuous catalyst recycling in the PtNPs-catalyzed hydrogenation of nitrobenzene. Inset illustrates the formation of triphasic flow in each microreactor 
to 150 times higher when the diameter was increased from $1 \mathrm{~mm}$ to $3.2 \mathrm{~mm}$ ). These explorations have laid the groundwork for the application of gas-liquid-liquid microreactors to meet production needs at the industrial scale. However, it must be admitted that due to the rather complex flow phenomena involved (e.g., the presence of bubbles and droplets in one flow), a precise manipulation across a multitude of parallel microchannel networks towards the optimized performance of the enlarged microreactor system remains a non-trivial task.

\section{Promising applications}

Although limited research progress has been demonstrated so far in the use of gas-liquid-liquid microreactors for performing efficient reaction processes, many potential applications are envisaged in this field. Gas-liquid-liquid reactions like hydrogenation (in the presence of either homogeneous or heterogeneous nanoparticle catalysts) have been shown with improved performance via flow processing in microreactors [11,30]. Similarly, triphasic hydroformylation and carbonylation reactions of industrial relevance are promising candidates that can also benefit from such microreactor operation. Interestingly, gas-liquid-liquid flow is also relevant to biodiesel production in microreactors. For example, Sun et al. [34] studied the transesterification of cottonseed oil with base catalyst $\mathrm{KOH}$ dissolved in methanol under $60-80^{\circ} \mathrm{C}$ in a stainless steel capillary microreactor (inner diameter: $0.6 \mathrm{~mm}$ ) to produce fatty acid methyl ester (FAME) as an alternative and biobased transportation fuel. The system pressure decreased from $0.8 \mathrm{MPa}$ at the microreactor inlet to $0.1 \mathrm{MPa}$ at the outlet and bubbles appeared at $70{ }^{\circ} \mathrm{C}$ (Fig. 13). The in-situ generated bubbles worked as additional agitators and further intensified the mass transfer between methanol and oil phases, but also made the gas-liquid or liquid-liquid interfacial area too difficult to quantify. From this perspective, addition of inert bubbles into the system before the reaction start would help to 'organize' the evaporated gas phase and improve the process controllability. The above findings also indicate that a good understanding of gas-liquid-liquid microreactors in terms of transport and reaction characteristics would help to optimize the microreactor performance in the promising biodiesel production.

Regarding reaction-extraction coupling, gas-liquid-liquid flow processing in microreactors opens a new avenue for the valorization of biomass and its derivatives towards the production of biobased chemicals. Two promising examples include the glucose oxidation to formic acid (a widely used commodity chemical in the chemical, agricultural, textile, leather, pharmaceutical and rubber industries) and lignin oxidation to vanillin (a flavoring agent with a wide range of applications in food industry and perfumery). The oxidation of glucose (readily available from biomass, e.g., via cellulose hydrolysis) using molecular oxygen could reach a formic acid yield (ca. 50-60\%) under mild reaction conditions (e.g., $363 \mathrm{~K}, 20-30$ bar $\mathrm{O}_{2}$ pressure, $\mathrm{H}_{8}\left[\mathrm{PV}_{5} \mathrm{MO}_{7} \mathrm{O}_{40}\right]$ as homogeneous polyoxometalate catalyst in the aqueous phase [75]). Reichert et al. [76] reported that via coupling the aqueous phase reaction with the in-situ organic phase (e.g., 1-hexanol) extraction of formic acid, the formic acid yield could be increased to $85 \%$ over reaction conditions mentioned above, due to the in-situ extraction avoiding $\mathrm{pH}$ decrease in the aqueous phase that is detrimental for the formic acid selectivity. Liu et al. [77] reported that the yield of vanillin synthesized from the oxidation of lignin (the third major component of lignocellulosic biomass) under $175^{\circ} \mathrm{C}$ and 30 bar $\mathrm{O}_{2}$ pressure could be improved up to $10 \%-14 \%$ by the reactionextraction coupling which minimized the vanillin overoxidation in the aqueous phase, with $\mathrm{CuSO}_{4}$ as catalyst dissolved in mixed phosphate solvent and MIBK as extractant. Both reaction results were reported in conventional reactor setups. A switch to gas-liquid-liquid microreactors may offer a number of opportunities for the intensification of both reactions towards obtaining the enhanced product yield, given the mass transfer intensification potential (e.g., fast reactant transport and product extraction rates) and the precise flow manipulation (e.g., residence time control for a desired product selectivity).

Inert gas assisted liquid-liquid physical extraction has been demonstrated in microreactors [22, 39] for improved process efficiency, and an extension to the reactive extraction case is a logic next step. In this regard, the reactive extraction of biobased organic acids is particularly interesting. For example, liquidliquid extraction under slug flow in microreactors has been shown to efficiently extract lactic acid (an important biobased chemical used for the commercial production of bioplastics) from the aqueous phase using tri-n-octylamine (TOA) as extractant in $\mathrm{n}$-octanol, which represents an attractive alternative for the isolation of lactic acid from fermentation broths [15]. The addition of an inert gas to further assist such reactive extraction in microreactors is expected to bring additional benefits in the overall efficiency increase as well as the reduced use of organic solvent, thus leading to a more sustainable process.

\section{Summarized outlook}

Gas-liquid-liquid three-phase systems in microreactors have shown promising applications in the intensification of various reaction processes, including among others triphasic reactions (using either homogeneous or heterogeneous catalysts), the coupling between a gas-liquid reaction and the in-situ liquidliquid extraction, inert gas assisted liquid-liquid reactions and particle synthesis under three-phase flow. Microreactors are able to well control the three-phase flow patterns (e.g., typically gas-liquid-liquid slug flow) and provide substantially enhanced (gas-liquid and/or liquid-liquid) mass transfer rates, which allows the reaction system performance to be further improved and optimized compared with their macroscale counterparts.

There are still many knowledge gaps that remain to be filled in order to realize a precise manipulation of gas-liquid-liquid threephase flow in microreactors towards their promising applications. 

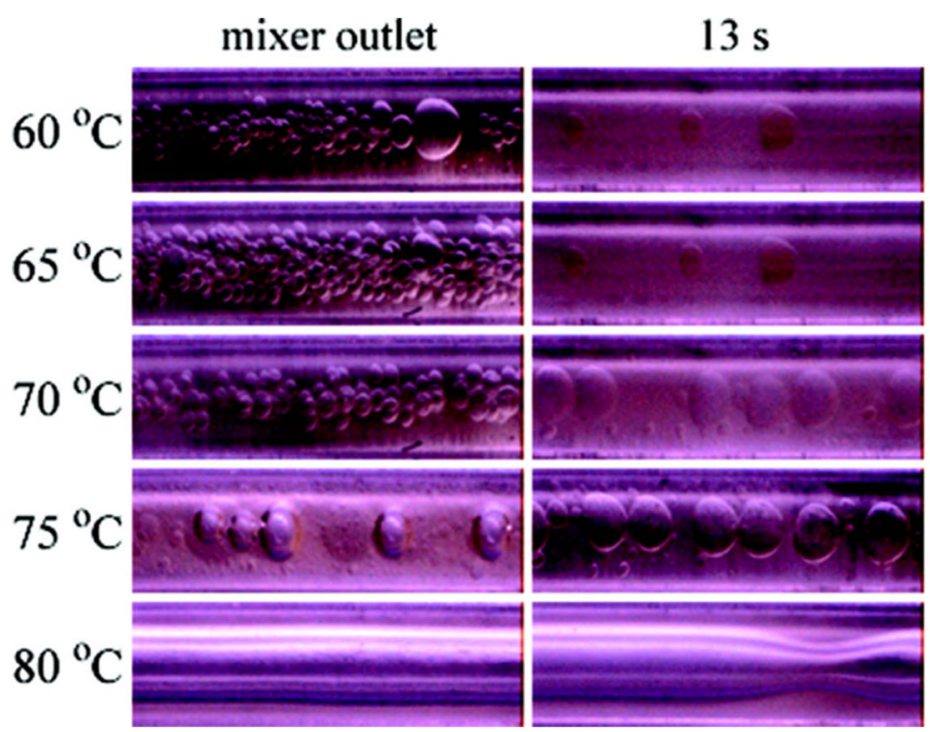

Fig. 13 Flow patterns observed during the transesterification of cottonseed oil with base catalyst $\mathrm{KOH}$ in the microreactor [34]. The reaction was conducted under $60-80{ }^{\circ} \mathrm{C}$ at multiple residence times.

A good understanding into the microreactor system performance highly relies on an in-depth knowledge of the underlying hydrodynamics and the associated mass transfer property, which is currently still not largely available. Due to the high analogy between two-phase (gas-liquid or liquid-liquid) and three-phase (gas-liquid-liquid) microflows [17], the established transport knowledge in the former case certainly sheds important light herein. It is thus expected that the balance among interfacial, inertial and viscous forces also plays an important role in determining the phase dispersion within three-phase flow through microreactors $[13,23,43,50,53,54]$. This implies that for designing and studying three-phase microflow, some important parameters (e.g., capillary number, Weber number and Reynolds number, the phase flow rate ratios) deserve much research attention $[18,50]$. When it comes to three-phase mass transfer characterization in microreactors, dimensionless numbers to consider under study include among others Sherwood and Schmidt numbers [42], and the development of a reasonable mass transfer correlation should be preferably based on a mechanistic understanding into the inner mass transfer details $[12,15]$ (e.g., in terms of the transport within bubbles/droplets/liquid slugs and at interfaces). Moreover, the scale-up of gas-liquid-liquid microreactors to meet the industrial production need is not a trivial task, especially when a large number of parallelized microchannel networks are present given the usual presence of multiple droplets and bubbles in one flow. Thus, substantial research efforts are required in order to address this challenge as well.

So far, somewhat limited research progress has been demonstrated regarding the use of gas-liquid-liquid microreactors for carrying out efficient reaction processes. Nevertheless, it is envisaged that the industry would welcome this emerging technology, as on one hand gas-liquid-liquid flow processing in microreactors opens a number of opportunities to perform
Gas bubbles started to present under $70^{\circ} \mathrm{C}$, and gas-liquid-liquid annular flow was formed at 75 and $80{ }^{\circ} \mathrm{C}$

various triphasic reactions that are of industrial relevance (like hydrogenation, hydroformylation) and on the other hand it opens a new avenue for the valorisation of biomass towards value-added chemicals and fuels synthesis (e.g., via an efficient reaction-extraction coupling for the selective oxidation of glucose or lignin) that facilitates the transition to a biorefinery.

Acknowledgements This work was financially supported by the University of Groningen (startup package in the area of green chemistry and technology for Jun Yue), and the National Natural Science Foundation of China (Nos. 91634204 and U1608221). Yanyan Liu would like to acknowledge the China Scholarship Council for the financial support (No. 201704910487) of her study at the University of Groningen.

\section{Compliance with ethical standards}

Conflict of interest On behalf of all authors, the corresponding author states that there is no conflict of interest.

Open Access This article is licensed under a Creative Commons Attribution 4.0 International License, which permits use, sharing, adaptation, distribution and reproduction in any medium or format, as long as you give appropriate credit to the original author(s) and the source, provide a link to the Creative Commons licence, and indicate if changes were made. The images or other third party material in this article are included in the article's Creative Commons licence, unless indicated otherwise in a credit line to the material. If material is not included in the article's Creative Commons licence and your intended use is not permitted by statutory regulation or exceeds the permitted use, you will need to obtain permission directly from the copyright holder. To view a copy of this licence, visit http://creativecommons.org/licenses/by/4.0/.

\section{References}

1. Chaudhari RV, Bhattacharya A, Bhanage BM (1995) Catalysis with soluble complexes in gas-liquid-liquid systems. Catal Today 24(12):123-133 
2. Widianto AY, Aubin J, Xuereb C, Poux M (2019) Gas-liquid-liquid reactions: contacting mechanisms and effective process technologies. Catal Today. https://doi.org/10.1016/j.cattod.2019.02.064

3. Grosselin JM, Mercier C, Allmang G, Grass F (1991) Selective hydrogenation of a, $\beta$-unsaturated aldehydes in aqueous organic two-phase solvent systems using ruthenium or rhodium complexes of sulfonated phosphines. Organometallics 10(7):2126-2133

4. Hablot I, Jenck J, Casamatta G, Delmas H (1992) Gas-liquid-liquid reaction using water soluble catalyst. Chem Eng Sci 47:2689-2694

5. Purwanto P, Delmas H (1995) Gas-liquid-liquid reaction engineering: hydroformylation of 1-octene using a water soluble rhodium complex catalyst. Catal Today 24(1):135-140

6. Panda AG, Jagtap SR, Nandurkar NS, Bhanage BM (2008) Regioselective hydroformylation of allylic alcohols using $\mathrm{Rh} /$ $\mathrm{PPh}_{3}$ supported ionic liquid-phase catalyst, followed by hydrogenation to 1,4-butanediol using $\mathrm{Ru} / \mathrm{PPh}_{3}$ supported ionic liquidphase catalyst. Ind Eng Chem Res 47(3):969-972

7. Gadge ST, Bhanage BM (2014) Recent developments in palladium catalysed carbonylation reactions. RSC Adv 4(20):10367-10389

8. Jensen KF (2017) Flow chemistry-microreaction technology comes of age. AIChE J 63(3):858-869

9. Elvira KS, i Solvas XC, Wootton RC, deMello AJ (2013) The past, present and potential for microfluidic reactor technology in chemical synthesis. Nature Chem 5(11):905-915

10. Yue J, Schouten JC, Nijhuis TA (2012) Integration of microreactors with spectroscopic detection for online reaction monitoring and catalyst characterization. Ind Eng Chem Res 51(45):14583-14609

11. Karan D, Khan SA (2019) Mesoscale triphasic flow reactors for metal catalyzed gas-liquid reactions. React Chem Eng 4:1331-1340

12. Liu Y, Yue J, Xu C, Zhao S, Yao C, Chen G (2020) Hydrodynamics and local mass transfer characterization under gas-liquid-liquid slug flow in a rectangular microchannel. AIChE J. 66:e16805

13. Liu Y, Yue J, Zhao S, Yao C, Chen G (2018) Bubble splitting under gas-liquid-liquid three-phase flow in a double T-junction microchannel. AIChE J 64(1):376-388

14. Yao C, Liu Y, Zhao S, Dong Z, Chen G (2017) Bubble/droplet formation and mass transfer during gas-liquid-liquid segmented flow with soluble gas in a microchannel. AIChE J 63(5):1727-1739

15. Susanti S, Winkelman JGM, Schuur B, Heeres HJ, Yue J (2016) Lactic acid extraction and mass transfer characteristics in slug flow capillary microreactors. Ind Eng Chem Res 55(16):4691-4702

16. Guo W, Heeres HJ, Yue J (2020) Continuous synthesis of 5hydroxymethylfurfural from glucose using a combination of $\mathrm{AlCl}_{3}$ and $\mathrm{HCl}$ as catalyst in a biphasic slug flow capillary microreactor. Chem Eng J 381:122754

17. Yue J, Rebrov EV, Schouten JC (2014) Gas-liquid-liquid threephase flow pattern and pressure drop in a microfluidic chip: similarities with gas-liquid/liquid-liquid flows. Lab Chip 14(9):16321649

18. Wang K, Lu Y, Qin K, Luo G, Wang T (2013) Generating gasliquid-liquid three-phase microflows in a cross-junction microchannel device. Chem Eng Technol 36(6):1047-1060

19. Chen Z, Xu J, Wang Y (2019) Gas-liquid-liquid multiphase flow in microfluidic systems - a review. Chem Eng Sci 202:1-14

20. Xu JH, Chen R, Wang YD, Luo GS (2012) Controllable gas/liquid/ liquid double emulsions in a dual-coaxial microfluidic device. Lab Chip 12(11):2029-2036

21. Tan J, Dong C, Lu YC, Xu JH, Luo GS (2012) Coupling process of oxidation and extraction in a gas-liquid-liquid microdispersion system for $\mathrm{H}_{2} \mathrm{O}_{2}$ synthesis. Ind Eng Chem Res 51(4):1834-1845

22. Chen Z, Sang F-N, Xu J-H, Luo G-S, Wang Y-D (2018) Efficient enrichment and recovery of rare earth elements with low concentration by membrane dispersion micro-extractors. Chem Eng and Process Process Intensif 127:127-135
23. Garstecki P, Fuerstman MJ, Stone HA, Whitesides GM (2006) Formation of droplets and bubbles in a microfluidic T-junctionscaling and mechanism of break-up. Lab Chip 6(3):437-446

24. Gunther A, Jensen KF (2006) Multiphase microfluidics: from flow characteristics to chemical and materials synthesis. Lab Chip 6(12): $1487-1503$

25. Yue J, Boichot R, Luo L, Gonthier Y, Chen G, Yuan Q (2010) Flow distribution and mass transfer in a parallel microchannel contactor integrated with constructal distributors. AIChE J 56:298-317

26. Al-Rawashdeh M, Yu F, Nijhuis TA, Rebrov EV, Hessel V, Schouten JC (2012) Numbered-up gas-liquid micro/milli channels reactor with modular flow distributor. Chem Eng J 207-208: 645-655

27. Adamo A, Beingessner RL, Behnam M, Chen J, Jamison TF, Jensen KF, Monbaliu J-CM, Myerson AS, Revalor EM, Snead DR (2016) On-demand continuous-flow production of pharmaceuticals in a compact, reconfigurable system. Science 352(6281):61-6728

28. Hatakeyama T, Chen DL, Ismagilov RF (2006) Microgram-scale testing of reaction conditions in solution using nanoliter plugs in microfluidics with detection by MALDI-MS. J Am Chem Soc 128(8):2518-2519

29. Önal $\ddot{Y}$, Lucas M, Claus P (2005) Application of a capillary microreactor for selective hydrogenation of $\alpha, \beta$-unsaturated aldehydes in aqueous multiphase catalysis. Chem Eng Technol 28(9): 972-978

30. Yap SK, Yuan Y, Zheng L, Wong WK, Zhang J, Yan N, Khan SA (2014) Rapid nanoparticle-catalyzed hydrogenations in triphasic millireactors with facile catalyst recovery. Green Chem 16(11): 4654-4658

31. Yap SK, Wong WK, Ng NXY, Khan SA (2016) Three-phase microfluidic reactor networks - design, modeling and application to scaled-out nanoparticle-catalyzed hydrogenations with online catalyst recovery and recycle. Chem Eng Sci 169:117-127

32. Cech J, Pribyl M, Snita D (2013) Three-phase slug flow in microchips can provide beneficial reaction conditions for enzyme liquidliquid reactions. Biomicrofluidics 7(5):54103

33. Sun P, Sun J, Yao J, Zhang L, Xu N (2010) Continuous production of biodiesel from high acid value oils in microstructured reactor by acid-catalyzed reactions. Chem Eng J 162(1):364-370

34. Sun P, Wang B, Yao J, Zhang L, Xu N (2010) Fast synthesis of biodiesel at high throughput in microstructured reactors. Ind Eng Chem Res 49(3):1259-1264

35. Ufer A, Sudhoff D, Mescher A, Agar DW (2011) Suspension catalysis in a liquid-liquid capillary microreactor. Chem Eng J 167(23):468-474

36. Zhang J, Wang K, Lin X, Lu Y, Luo G (2014) Intensification of fast exothermic reaction by gas agitation in a microchemical system. AIChE J 60(7):2724-2730

37. Wong WK, Yap SK, Lim YC, Khan SA, Pelletier F, Corbos EC (2017) Robust, non-fouling liters-per-day flow synthesis of ultrasmall catalytically active metal nanoparticles in a single-channel reactor. React Chem Eng 2:636-641

38. Nightingale AM, Phillips TW, Bannock JH, de Mello JC (2014) Controlled multistep synthesis in a three-phase droplet reactor. Nat. Commun 5:3777

39. Su Y, Chen G, Zhao Y, Yuan Q (2009) Intensification of liquidliquid two-phase mass transfer by gas agitation in a microchannel. AIChE J 55(8):1948-1958

40. Assmann N, von Rohr PR (2011) Extraction in microreactors: intensification by adding an inert gas phase. Chem Eng Process Process Intensif 50(8):822-827

41. Tan J, Lu YC, Xu JH, Luo GS (2013) Modeling investigation of mass transfer of gas-liquid-liquid dispersion systems. Sep Purif Technol 108:111-118 
42. Yue J, Chen G, Yuan Q, Luo L, Gonthier Y (2007) Hydrodynamics and mass transfer characteristics in gas-liquid flow through a rectangular microchannel. Chem Eng Sci 62(7):2096-2108

43. Wang K, Qin K, Wang T, Luo G (2015) Ultra-thin liquid film extraction based on a gas-liquid-liquid double emulsion in a microchannel device. RSC Adv 5(9):6470-6474

44. Rahman MT, Krishnamurthy PG, Parthiban P, Jain A, Khan SA (2013) Dynamically tunable nanoparticle engineering enabled by short contact-time microfluidic synthesis with a reactive gas. RSC Adv 3(9):2897-2900

45. Wang K, Li L, Xie P, Luo G (2017) Liquid-liquid microflow reaction engineering. React Chem Eng 2(5):611-627

46. Kreutzer MT, Kapteijn F, Moulijn JA, Heiszwolf JJ (2005) Multiphase monolith reactors: chemical reaction engineering of segmented flow in microchannels. Chem Eng Sci 60(22):58955916

47. Abiev RS (2013) Bubbles velocity, Taylor circulation rate and mass transfer model for slug flow in milli- and microchannels. Chem Eng J 227:66-79

48. Yao C, Dong Z, Zhang Y, Mi Y, Zhao Y, Chen G (2015) On the leakage flow around gas bubbles in slug flow in a microchannel. AIChE J 61(11):3964-3972

49. Wang K, Lu YC, Tan J, Yang BD, Luo GS (2010) Generating gas/ liquid/liquid three-phase microdispersed systems in double Tjunctions microfluidic device. Microfluid Nanofluid 8(6):813-821

50. Wang K, Qin K, Lu Y, Luo G, Wang T (2015) Gas/liquid/liquid three-phase flow patterns and bubble/droplet size laws in a double T-junction microchannel. AIChE J 61(5):1722-1734

51. Abolhasani M, Bruno NC, Jensen KF (2015) Oscillatory threephase flow reactor for studies of bi-phasic catalytic reactions. Chem Commun 51(43):8916-8919

52. Aoki N, Ando R, Mae K (2011) Gas-liquid-liquid slug flow for improving liquid-liquid extraction in miniaturized channels. Ind Eng Chem Res 50(8):4672-4677

53. Chen DL, Li L, Reyes S, Adamson DN, Ismagilov RF (2007) Using three-phase flow of immiscible liquids to prevent coalescence of droplets in microfluidic channels: criteria to identify the third liquid and validation with protein crystallization. Langmuir 23(4):2255-2260

54. Zhang Y, Shitta A, Meredith JC, Behrens SH (2016) Bubble meets droplet: particle-assisted reconfiguration of wetting morphologies in colloidal multiphase systems. Small 12(24):3309-3319

55. Schrimpf M, Esteban J, Rösler T, Vorholt AJ, Leitner W (2019) Intensified reactors for gas-liquid-liquid multiphase catalysis: from chemistry to engineering. Chem Eng J. https://doi.org/10.1016/j. cej.2019.03.133

56. Gallezot P, Richard D (1998) Selective hydrogenation of $\alpha, \beta$-unsaturated aldehydes. Catal Rev 40(1-2):81-126

57. Deshpande RM, Divekar SS, Bhanage BM, Chaudhari RV (1992) Activity of $\mathrm{HRh}(\mathrm{CO})\left(\mathrm{PPh}_{3}\right)_{3}$ catalyst in hydroformylation of allyl alcohol: effect of second immiscible liquid phase. J Mol Catal 75(1):L19-L22

58. Brilman DWF, van Swaaij WPM, Versteeg GF (1999) Gas-liquidliquid reaction engineering: the Koch synthesis of pivalic acid from iso- and tert-butanol; reaction kinetics and the effect of a dispersed second-liquid phase. Chem Eng Sci 54(21):4801-4809

59. Lü S, Mi Z, Wang L, Wang Y, Zhu Z, Fu S (2005) Experimental investigation and simulation of gas-liquid-liquid reactive extraction process for the production of hydrogen peroxide. Chem Eng Sci 60(22):6298-6306

60. Cheng Y, Wang L, Lü S, Wang Y, Mi Z (2008) Gas-liquid-liquid three-phase reactive extraction for the hydrogen peroxide preparation by anthraquinone process. Ind Eng Chem Res 47(19): $7414-7418$
61. Minotti M, Doherty MF, Malone MF (1998) Design for simultaneous reaction and liquid-liquid extraction. Ind Eng Chem Res 37(12):4748-4755

62. Hage R, Lienke A (2006) Applications of transition-metal catalysts to textile and wood-pulp bleaching. Angew Chem Int Ed Engl 45(2):206-222

63. Santacesaria E, Ferro R, Ricci S, Carra S (1987) Kinetic aspects in the oxidation of hydrogenated 2-ethyltetrahydroanthraquinone. Ind Eng Chem Res 26(1):155-159

64. Levenspiel O, Godfrey JH (1974) A gradientless contactor for experimental study of interphase mass transfer with/without reaction. Chem Eng Sci 29(8):1723-1730

65. Tan J, Du L, Lu YC, Xu JH, Luo GS (2011) Development of a gasliquid microstructured system for oxidation of hydrogenated 2ethyltetrahydroanthraquinone. Chem Eng J 171(3):1406-1414

66. Feng T-F, Tan J, Deng W-S, Su Y-F (2018) Intensification of highphase-ratio extraction via microbubble-agitation in gas-liquidliquid systems. Chem Eng Sci 177:270-283

67. Karande R, Schmid A, Buehler K (2011) Miniaturizing biocatalysis: enzyme-catalyzed reactions in an aqueous/organic segmented flow capillary microreactor. Adv Synth Catal 353(13):2511-2521

68. Aussillous P, Quéré D (2000) Quick deposition of a fluid on the wall of a tube. Phys Fluids 12(10):2367

69. Bretherton FP (1961) The motion of long bubbles in tubes. J Fluid Mech 10(2):166-188

70. Ładosz A, Rigger E, Rudolf von Rohr P (2016) Pressure drop of three-phase liquid-liquid-gas slug flow in round microchannels. Microfluid Nanofluid 20(3):20-49

71. Khan SA, Duraiswamy S (2009) Microfluidic emulsions with dynamic compound drops. Lab Chip 9(13):1840-1842

72. Rajesh VM, Buwa VV (2012) Experimental characterization of gas-liquid-liquid flows in T-junction microchannels. Chem Eng J 207-208:832-844

73. Rajesh VM, Buwa VV (2018) Volume-of-fluid simulations of gasliquid-liquid flows in minichannels. Chem Eng J 345:688-705

74. Adamson DN, Mustafi D, Zhang JX, Zheng B, Ismagilov RF (2006) Production of arrays of chemically distinct nanolitre plugs via repeated splitting in microfluidic devices. Lab Chip 6(9): 1178-1186

75. Wölfel R, Taccardi N, Bösmann A, Wasserscheid P (2011) Selective catalytic conversion of biobased carbohydrates to formic acid using molecular oxygen. Green Chem 13(10):2759

76. Reichert J, Brunner B, Jess A, Wasserscheid P, Albert J (2015) Biomass oxidation to formic acid in aqueous media using polyoxometalate catalysts - boosting FA selectivity by in-situ extraction. Energy Environ Sci 8(10):2985-2990

77. Liu S, Zhang C, Li L, Yu S, Xie C, Liu F, Song Z (2014) Application of dissociation extraction in oxidation degradation reaction of lignin. Ind Eng Chem Res 53(49):19370-19374

Publisher's note Springer Nature remains neutral with regard to jurisdictional claims in published maps and institutional affiliations.

Jun Yue received his PhD degree from Université de Savoie in 2008. His $\mathrm{PhD}$ work was focused on gas-liquid microreactors, supported by a joint PhD program with Dalian Institute of Chemical Physics, Chinese Academy of Sciences. From 2009 to 2014, he worked as a postdoc at Eindhoven University of Technology, where his research was extended to cover liquid-liquid and gas-liquid-liquid microreactor systems. Since August 2014, he has moved to the University of Groningen and is currently an associate professor in green process intensification. His research interests involve the development of novel reactor concepts and their uses for sustainable chemical conversion. 